\title{
The Thermal Expansion Behavior of Unalloyed Plutonium
}

\section{Fred W. Schonfeld \\ Raymond E. Tate}

\section{DISCLAIMER}

This report was prepared as an account of work sponsored by an agency of the United States Government. Neither the United States Government nor any agency thereof, nor any of their employees, makes any warranty, express or implied, or assumes any legal liability or responsibility for the accuracy, completeness, or usefulness of any information, apparatus, product, or process disclosed, or represents that its use would not infringe privately owned rights. Reference herein to any specific commercial product, process, or service by trade name, trademark, manufacturer, or otherwise does not necessarily constitute or imply its endorsement, recommendation, or favoring by the United States Government or any agency thereof. The views and opinions of authors expressed herein do not necessarily state or reflect those of the United States Government or any agency thereof.

b

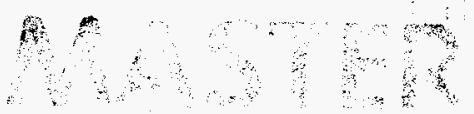




\section{DISCLAMMER}

Portions of this document may be illegible in electronic image products. Images are produced from the best available original document. 



\section{Table of Contents}

I. INTRODUCTION
A. Caveats
B. Technique

II. COMPOSITE APPROXIMATIONS OF LENGTH AND VOLUME CHANGE

Table I Plutonium Transition Temperatures

Table II Expansion Coefficients of Solid Plutonium Phases

III. LENGTH AND VOLUME CHANGES IN UNALLOYED PLUTONIUM ....... 5
A. Alpha Plutonium 5
B. Beta Plutonium 5
C. Gamma Plutonium 6
D. Unalloyed Delta Plutonium 7
E. Delta Prime Plutonium 8
F. Epsilon Plutonium 8
G. Liquid Plutonium 8

IV. FINAL NOTE 


\section{List of Figures}

Figure 1 Composite Approximation of the Length of Plutonium ................ 10

Figure 2 Composite Approximation of the Volume of Plutonium .................11

Figure 3a Alpha Plutonium Expansion, Celsius .......................................... 12

Figure 3b Alpha Plutonium Expansion, Kelvin ..........................................13

Figure 4a Average Expansion Coefficient - Alpha Plutonium, Celsius......... 14

Figure 4b Average Expansion Coefficient - Kelvin ................................... 15

Figure 5a Engineering Expansion Coefficient - Alpha Plutonium, Celsius .... 16

Figure 5b Engineering Expansion Coefficient - Kelvin .............................. 17

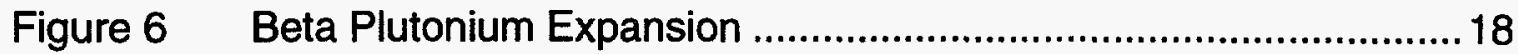

Figure 7 Average Expansion Coefficient - Beta Plutonium ....................... 19

Figure 8 Engineering Expansion Coefficient - Beta Plutonium .................. 20

Figure 9 Gamma Plutonium Expansion ...................................................21

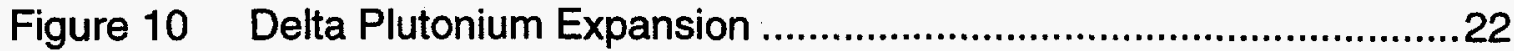

Figure 11 Average Expansion Coefficient - Delta Plutonium ...................... 23

Figure 12 Engineering Expansion Coefficient - Delta Plutonium ................. 24

Figure 13 Extended Temperature Range Delta Plutonium Expansion .......... 25

Figure 14 Average Expansion Coefficient - Extended Temperature

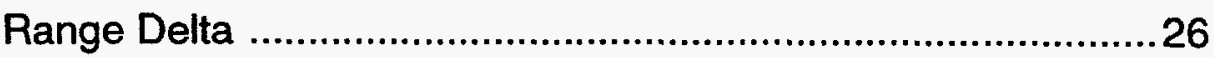

Figure 15 Engineering Expansion Coefficient - Extended Range Delta Plutonium

Figure 16 Delta Prime Plutonium Expansion .............................................28

Figure 17 Average Expansion Coefficient - Delta Prime Plutonium .............. 29

Figure 18 Engineering Expansion Coefficient - Delta Prime Plutonium ........ 30

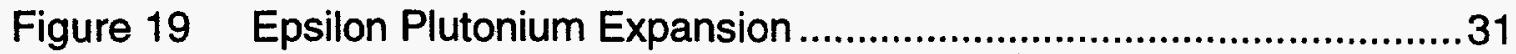

Figure 20 Liquid Plutonium Expansion ........................................................32 


\title{
THE THERMAL EXPANSION BEHAVIOR OF UNALLOYED PLUTONIUM
}

\author{
by
}

Fred W. Schonfeld and Raymond E. Tate

\begin{abstract}
Information and data concerning the thermal expansion characteristics of the solid and liquid phases of unalloyed plutonium have been collected from published and unpublished sources and evaluated, and are presented to provide increased availability in compact form.
\end{abstract}

\section{INTRODUCTION}

Numerical equations describing the dimensional changes of the seven condensed phases (six plus the liquid) of "unalloyed" plutonium metal as functions of temperature have been developed from experimental data (both published and unpublished) viewed from the personal experiences of the authors. The dimensions utilized in the $L$ vs. $T$ curves are the physical lengths of the experimental specimens reduced to the comparative length at the reference

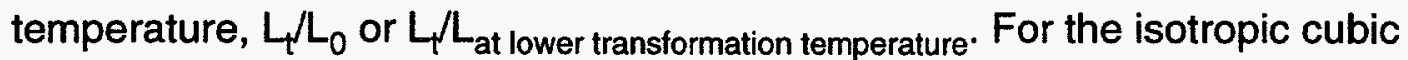
phases, however, the usefulness of the curves is increased by using lattice parameters in the plots. The derived curves for the anisotropic phases were compared to dimensions obtained from $\mathrm{X}$-ray or neutron diffraction measurements at various isolated temperatures in order to verify that the dilatometric data represented a reasonable approximation to crystallographic randomness.

The average coefficient of expansion is usually defined, (Hidnert and Souder, $1950)$, as

$$
t_{1} \alpha_{t_{2}}=\frac{L_{2}-L_{1}}{L_{0}\left(t_{2}-t_{1}\right)}=\frac{\Delta L}{L_{0} \cdot \Delta t}
$$


and the engineering (or instantaneous) coefficient as

$$
a_{t}=\lim _{t_{1} \rightarrow t_{2}} \frac{L_{2}-L_{1}}{L_{0}\left(t_{2}-t_{1}\right)}=\frac{d L}{L_{0}(d t)}
$$

Accepted practice for most materials utilizes the length or lattice parameters at $0^{\circ} \mathrm{C}$ as the reference length $\left[L_{0}\right.$ or $\left.a_{0}\right]$. (However, if a phase change occurs at a temperature higher than $\mathrm{T}=0$, the appropriate reference length becomes the length at the lower end of the temperature range of the new phase).

However, if $L_{0}$ is the length of the body at $0^{\circ} \mathrm{C}$ the length at any temperature $t^{\circ} \mathrm{C}$ (absent phase changes) may be represented by

$$
L_{t}=L_{0}\left(1+a t+b t^{2}+\ldots\right)
$$

where $a, b, \ldots$ are constants. Thus, the instantaneous coefficient may also be derived by differentiation and represented as follows:

$$
\alpha_{t}=\frac{a+2 b t+\ldots}{L_{0}}
$$

The "true instantaneous coefficient" is defined as

$$
\alpha_{T i}=\frac{a+2 b t+\ldots}{L_{t}},
$$

but since the difference between $L_{t}$ and $L_{0}$ is quite small in the cases discussed here, the two coefficients $\left(\alpha_{T i}\right.$ and $\left.\alpha_{E n g}\right)$ are the same within experimental variation. Obviously, for a given expansion curve $\alpha_{T_{1}} / \alpha_{\mathrm{Eng}}=\mathrm{L}_{0} / \mathrm{L}_{\mathrm{T}}$. Therefore, we have chosen not to include plots for $\alpha_{T \text { i. }}$.

Within the temperature range of a given isotropic phase and defining the lower transformation temperature as the reference temperature, the volume expansion coefficient is approximately three times the linear expansion coefficient $\left(\alpha_{V}=3 \alpha_{L}\right)$.

\section{A. Caveats}

1. Reduction and processing of plutonium must always be carried out in small lots to guard against criticality incidents. Therefore, batch-to-batch variations in purity levels have been inevitable. Until more effective purification and operational techniques have been developed, we must assume that results of different investigators will not be exactly reproducible. 
Many of the results of chemical analysis of the samples utilized have been misplaced or were never reported. We believe that the unalloyed metal used by most investigators contained $200-500 \mathrm{ppm}$ of metallic impurities ( $\mathrm{Fe}, \mathrm{Ni}, \mathrm{Si}$, etc.) plus $\mathrm{C}$ and $\mathrm{O}_{2}$.

2. At present the heat of radioactive decay of the available plutonium isotopes makes specimen temperature uniformity difficult to approach and to measure. This introduces an element of uncertainty into the most carefully carried out measurements. Further, differing isotopic ratios influence responses in experiments in which temperature control and/or measurement are important.

3. Four of the six solid phases of plutonium ( $\alpha, \beta, \gamma$ and $\delta^{\prime}$ ) are crystallographically anisotropic and exhibit differing axial expansion behaviors. Therefore, dilatometric measurements can differ from X-ray data if substantial preferred orientation exists. However, the few available data suggest that the alpha phase is the only plutonium phase in which significant preferred orientation can easily be produced and retained (within its temperature range of stability).

\section{B. Technique}

Numerical equations for the lattice constant/temperature relations of the two isotropic solid phases (delta and epsilon plutonium) and linear or volumetric changes vs. temperature for the four anisotropic solid phases and the liquid phase have been developed from data originally reported as 1) tables, 2) equations (values calculated using MathCAD ${ }^{\mathrm{TM}}$ ), and 3) X-Y plots (data points digitized using SigmaScan ${ }^{\mathrm{TM}}$ ). Lattice dimensions or linear dimensions were plotted as functions of temperature using TableCurve ${ }^{\mathrm{TM}}$, and appropriate polynomial equations were fitted to the plotted data using procedures available in TableCurve. Average and engineering linear expansion coefficients were calculated from the dimension/temperature equations using the capabilities of MathCAD. 


\section{COMPOSITE APPROXIMATIONS OF LENGTH AND VOLUME CHANGES}

Figures 1 and 2 are intended to provide generalized views of the effects of both phase changes and individual phase thermal expansions on specimen lengths and volumes. Values of the lengths and volumes at phase transitions were calculated from the thermal expansion curves plus the densities calculated from $\mathrm{X}$-ray diffraction measurements.

Tables I and II are included here as an aid in the interpretation of Figures 1 and 2. The length and volume changes at temperature were calculated from data that we judge to be the best available at this time, but it is obvious that small changes in impurity levels can produce changes in both transition temperatures and values of $\Delta \mathrm{L}$ and $\Delta \mathrm{V}$. For practical use we suggest rounding the $\Delta \mathrm{L}$ and $\Delta V$ numbers to one decimal place.

\section{TABLE I}

Plutonium Transition Temperatures with Calculated Length and Volume Changes

\begin{tabular}{|c|c|c|c|}
\hline & Approximate $T_{t}$ & $\Delta \mathbf{L}(\%)$ & $\Delta V(\%)$ \\
\hline$\alpha \rightarrow \beta$ & $393 \mathrm{~K} \quad 120^{\circ} \mathrm{C}$ & 3.06 & 9.45 \\
\hline$\beta \rightarrow \gamma$ & $483 \mathrm{~K} \quad 210^{\circ} \mathrm{C}$ & 0.96 & 2.90 \\
\hline$\gamma \rightarrow \delta$ & $588 \mathrm{~K} \quad 315^{\circ} \mathrm{C}$ & $\overline{2.13}$ & 6.53 \\
\hline$\delta \rightarrow \delta^{\prime}$ & $723 \mathrm{~K} \quad 450^{\circ} \mathrm{C}$ & -0.21 & -.62 \\
\hline$\delta^{\prime} \rightarrow \varepsilon$ & $753 \mathrm{~K} \quad 480^{\circ} \mathrm{C}$ & -0.75 & -2.22 \\
\hline$\varepsilon \rightarrow L$ & $913 \mathrm{~K} \quad 640^{\circ} \mathrm{C}$ & -0.79 & -2.34 \\
\hline
\end{tabular}

TABLE II

\section{Average Expansion Coefficients of the Six Solid Plutonium Phases} over Their Approximate Temperature Ranges of Stability

\begin{tabular}{|c|c|c|c|}
\hline Phase & $T_{1} \rightarrow T_{2}(\mathbf{K})$ & $T_{1} \rightarrow T_{2}(C)$ & $\alpha\left(T_{1} \rightarrow T_{2}\right) \times 10^{-6}$ \\
\hline$\alpha$ & $0 \rightarrow 393$ & $-273 \rightarrow 120$ & 37.8 \\
\hline$\beta$ & $393 \rightarrow 483$ & $120 \rightarrow 210$ & 43.2 \\
\hline$\gamma$ & $483 \rightarrow 580$ & $210 \rightarrow 315$ & 34.7 \\
\hline$\delta$ & $580 \rightarrow 723$ & $315 \rightarrow 450$ & -9.0 \\
\hline$\delta^{\prime}$ & $723 \rightarrow 753$ & $450 \rightarrow 480$ & -66.0 \\
\hline$\varepsilon$ & $753 \rightarrow 913$ & $480 \rightarrow 640$ & 36.5 \\
\hline
\end{tabular}




\section{LENGTH AND VOLUME CHANGES IN UNALLOYED PLUTONIUM}

\section{A. Alpha Plutonium}

The structure of the alpha phase of plutonium is simple monoclinic $\left(\mathrm{P} 2_{1} / \mathrm{m}\right)$, with $a=0.6183 \mathrm{~nm}, \mathrm{~b}=0.4822 \mathrm{~nm}$, and $\mathrm{c}=1.0963 \mathrm{~nm}$, and with the interaxial angle $\beta=101.79^{\circ}$, all at $21^{\circ} \mathrm{C}$, Zachariasen and Ellinger (1957). It is stable between $0 \mathrm{~K}$ and $\sim 393 \mathrm{~K}\left(-273^{\circ} \mathrm{C}\right.$ and $\left.\sim 120^{\circ} \mathrm{C}\right)$, but below $\sim 60 \mathrm{~K}$ stored radiation damage causes some minor expansion of the lattice that is of little consequence unless the holding times at very low temperatures are quite long (Jacquemin and Lallement, 1970, and Marples, et al. 1970).

Because the three crystal axes differ significantly in their expansion behaviors (Zachariasen and Ellinger, 1963, pp. 777-783) $\left(\alpha_{1}(20-100 \mathrm{C})=\sim 60 \times 10^{-6}\right.$, $\left.\alpha_{b}=\alpha_{2(20-100 \mathrm{C})}=-75 \times 10^{-6}, \alpha_{3(20-100 \mathrm{C})}=\sim 29 \times 10^{-6}\right)$ bulk thermal expansion can be influenced by the presence of any significant degree of preferred orientation.

Figures $3 a$ and $3 b$, Alpha Plutonium Expansion, were computer-generated using a combination of data digitized from the X-Y plots of Cramer, et al. (1961) and Lee, et al. (1967), values calculated from the equations of Sandenaw (1961), and values from the tables of Lallement and Solente (1967), Wick (1967), and Lawson, et al. (1994). See also Figures 4a, 4b, 5a, and 5b.

\section{B. Beta Plutonium}

The structure of the beta phase of plutonium can be described as body-centered monoclinic $\left(12 / \mathrm{m}^{1}\right)$, with $\mathrm{a}=0.9284 \mathrm{~nm}, \mathrm{~b}=1.0463 \mathrm{~nm}, \mathrm{c}=0.7859 \mathrm{~nm}$, and $\mathrm{a}$ $\beta$-angle $=92.13^{\circ}$, all at $190^{\circ} \mathrm{C}$ (Zachariasen and Ellinger, 1963, pp.369-375). Again, as is the case for the alpha phase, the three crystallographic axes have different thermal expansion behaviors $-\alpha_{1} \sim 94 \times 10^{-6}, \alpha_{2}=\alpha_{b} \sim 14 \times 10^{-6}$, and $\alpha_{3} \sim 19 \times{ }^{-6}$ (for the temperature range $93^{\circ} \mathrm{C}-190^{\circ} \mathrm{C}$ ) (Zachariasen and Ellinger, 1959). Thus, bulk expansion measurements are subject to error if preferred orientation is present.

\footnotetext{
'Although space group $12 / \mathrm{m}$ is not one of the "standard" space groups tabulated in the International Union of Crystallography (1952), its notation is retained to obtain a $\beta$-angle of approximately $90^{\circ}$.
} 
Additionally, because the compressive creep rate of $\beta$ transformed from $\alpha$ is 50-500 times greater than that of $\beta$ transformed from $\gamma$ (Nelson, 1967), dilatometric measurements probably are best made by first transforming the specimen to the gamma phase, cooling to produce $100 \% \beta$, and then heating the specimen adiabatically. The cause of this anomalous creep behavior has not been fully explored, but its existence clearly makes the use of $X$-ray diffraction measurements a superior technique in this case.

The beta plutonium expansion curve presented in Figure 6 has been compiled from the X-Y plots of Cramer, et al. (1961) and Nelson (1967) and from the tables of Zachariason and Ellinger (1959) and Wick (1967). See also Figures 6 , 7 , and 8.

\section{Gamma Plutonium}

The gamma phase of plutonium is face-centered orthorhombic (Fddd), with $a=0.3159 \mathrm{~nm}, b=0.5768 \mathrm{~nm}$, and $c=1.0162 \mathrm{~nm}$ (all at $235^{\circ} \mathrm{C}$ ). The range of stability for $\gamma$ is from $\sim 205^{\circ} \mathrm{C}$ to $\sim 315^{\circ} \mathrm{C}$, but it can be retained down to $\sim 190^{\circ} \mathrm{C}$. $\alpha_{a}=\alpha_{1}=-19.7 \times 10^{-6}, \alpha_{b}=\alpha_{2}=39.5 \times 10^{-6}$, and $\alpha_{c}=\alpha_{3}=84.3 \times 10^{-6}$ (for the temperature range $210^{\circ} \mathrm{C}-310^{\circ} \mathrm{C}$ ) (Zachariasen and Ellinger, 1955). Arithmetic averaging of the coefficients listed above yields $\alpha_{p(210 c-310 c)}=34.7 \times 10^{-6}$.

The data points plotted in Figure 9, Gamma Plutonium Expansion, were calculated using the equation published by Zachariason and Ellinger (1955) and from the table of Wick (1967).

Because the length vs. temperature curve for the gamma phase is a straight line, the average and engineering linear expansion coefficients are identical and constant. Thus

the average linear expansion coefficient is

$\alpha_{\text {avg }}=34.7 \cdot 10^{-6} ; \alpha(206 \rightarrow \mathrm{T})$,

and the engineering linear expansion coefficient is

$\alpha_{\text {eng }}=34.7 \cdot 10^{-6} ; \alpha_{e}(206 \rightarrow \mathrm{T})$. 


\section{Unalloyed Delta Plutonium}

The delta phase of plutonium is face-centered cubic ( $\mathrm{Fm} 3 \mathrm{~m})$ and normally exists over the temperature range of $\sim 315^{\circ} \mathrm{C}-452^{\circ} \mathrm{C}$. At $320^{\circ} \mathrm{C}$ the unit cell edge is $0.46371 \mathrm{~nm}$. At temperature, delta plutonium is easily deformed plastically and so must be only lightly loaded in order to obtain good dilatometric data. We chose to use $X$-ray diffraction data exclusively. The most extensive $X$-ray diffraction data are those of Ellinger (1957). His data extend from $317^{\circ} \mathrm{C}$ to $440^{\circ} \mathrm{C}$ and were interpreted as a linear function of temperature

$$
a=4.63790+/-0.00012-(4.01+/-0.15) \times 10^{-5}(T-300) \text {. }
$$

However, X-ray data obtained from alloys stabilized by additions of aluminum, cerium, or gallium extrapolated to zero alloy content suggest that the curve shown in Figure 10 may represent an improved description of the thermal expansion of the delta phase between $315^{\circ} \mathrm{C}$ and $450^{\circ} \mathrm{C}$. The differences are encompassed by the maximum and minimum values of Ellinger's equation. For most purposes these differences are not significant.

Other investigators, Pascard (1961), Abramson (1961), and Lee and Marden (1961), have observed that the $\delta \rightarrow \gamma$ transformation of unalloyed delta plutonium is often depressed by $50^{\circ}-60^{\circ} \mathrm{C}$ during cooling. Utilizing the same extrapolation technique of alloy data described above, points have been obtained for temperatures as low as $0^{\circ} \mathrm{C}$, enabling construction of the tentative curve shown in Figure 13. This curve suggests only that if the delta phase of unalloyed plutonium could be retained to temperatures significantly below the equilibrium $\delta \rightarrow \gamma$ transformation temperature $\left(-315^{\circ} \mathrm{C}\right)$, its expansion behavior might be similar to that illustrated in Figures 13, 14, and 15.

The calculated expansion coefficients are shown in Figures 11, 12, 14, and 15. The sensitivities of the coefficients to small changes in the slope of the length vs. temperature plots are well illustrated by comparing the average expansion coefficient $\left(\alpha_{320-T}\right)$ of Figure 11 to Ellinger's constant value of $-8.6 \times 10^{-6}$. 


\section{E. Delta Prime Plutonium}

The delta prime phase of unalloyed plutonium is body-centered tetragonal $\left(14 / \mathrm{mmm}\right.$ ), with $a=0.33261 \mathrm{~nm}$ and $\mathrm{c}=0.44630 \mathrm{~nm}$ at $450^{\circ} \mathrm{C}$ (Elliott and Larson, 1961). The axial expansion coefficients are radically different, $\alpha_{\mathrm{a}(450 \mathrm{c}-480 \mathrm{C})}$ $=444.8+/-12.1 \times 10^{-6}$ and $\alpha_{c}(450 \mathrm{c}-480 \mathrm{c})=-1063.5+/-18.2 \times 10^{-6}$, with an arithmetic average of $-58 \times 10^{-6}$, (a poor approximation). Using median values to calculate unit cell volumes vs. temperature, converting to equivalent cubic cells, and comparing them with the equivalent cube edge at $452^{\circ} \mathrm{C}$ the curves of Figure 16, Figure 17, and Figure 18 were constructed $\left[\left(I_{450}+\alpha_{p} \Delta T\right)^{3}=\right.$ $\left.\left(I_{a} 450+\alpha_{a} \Delta T\right)^{2}\left(I_{c 450}+\alpha_{c} \Delta T\right)\right]$. This method yields the value of $-65.1 \times 10^{-6}$ for the temperature interval $450^{\circ} \mathrm{C}-480^{\circ} \mathrm{C}$, in good agreement with the value given by Elliott and Larson (1961) as $-65.6+/-10.1 \times 10^{-6}$ and also with the value $-63+/-5 \times 10^{-6}$ given by Abramson (1961).

\section{F. Epsilon Plutonium}

The epsilon phase of plutonium is body-centered cubic ( $a=0.36361 \mathrm{~nm}$ at $490^{\circ} \mathrm{C}$ ) over the range $480^{\circ} \mathrm{C}$ to $640^{\circ} \mathrm{C}$. Its expansion curve is linear, as shown in Figure 19. The values used in plotting this figure are taken from Ellinger's (1956) $X-Y$ plot of lattice constants and the table of Wick (1967).

The length vs. temperature curve for epsilon plutonium is a straight line. Thus, the average and engineering linear expansion coefficients are equal and constant.

The average linear expansion coefficient is $\alpha_{\text {avg }}=36.5 \cdot 10^{-6} ; \alpha(480 \rightarrow \mathrm{T})$.

The engineering linear expansion coefficient is $\alpha_{\text {eng }}=36.5 \cdot 10^{-6} ; \alpha_{e}(480 \rightarrow \mathrm{T})$.

\section{G. Liquid Plutonium}

The expansion curve for liquid plutonium metal, Figure 20, was calculated from the average of the density vs. temperature measurements published by Serpan and Wittenberg (1961) and by Olsen, et al. (1959). These data were also reported by Wick (1967). Obviously, measurements of the liquid density are simple in concept but extremely difficult to execute. Additionally, purity level is an important variable in all density measurements. 
The existing data suggest that density vs. temperature is a straight line function. If this is so, there must be some curvature in a precise plot of volume vs. temperature, but the deviation from a straight line is so small that it can reasonably be neglected.

The accuracy of the data does not justify use of the exact equation to convert the volume expansion coefficient to the linear coefficient. Therefore, the approximation $\alpha_{V}=3 \alpha_{L}$ was used. (The difference in this case is only about $+/-0.1 \times 10^{-6}$.)

The average liquid expansion coefficients are as follows:

average volume expansion coefficient

$\alpha_{\text {avg }}=90.352 \cdot 10^{-6} ; \alpha(640 \rightarrow T)\left[90.352\right.$ rounded to $\left.90.4 \times 10^{-6}\right]$ and

average linear expansion coefficient

$\alpha_{\text {avg }}=30.1 \cdot 10^{-6} ; \alpha(640 \rightarrow \mathrm{T})\left[90.4 / 3=30.1 \times 10^{-6}\right]$

The engineering liquid expansion coefficients are as follows:

engineering volume expansion coefficient

$\alpha_{\text {eng }}=90.4 \cdot 10^{-6} ; \alpha_{e}(640 \rightarrow T)$ and

engineering linear expansion coefficient

$\alpha_{\text {eng }}=30.1 \cdot 10-6 ; \alpha_{e}(640 \rightarrow \mathrm{T})$.

\section{FINAL NOTE}

Because the delta phase of plutonium has more desirable metallurgical characteristics than the other solid phases and can be stabilized by modest alloy addition, similar expansion information for several such alloys will be presented in a subsequent report. 
(Thermal expansions and phase transformations)

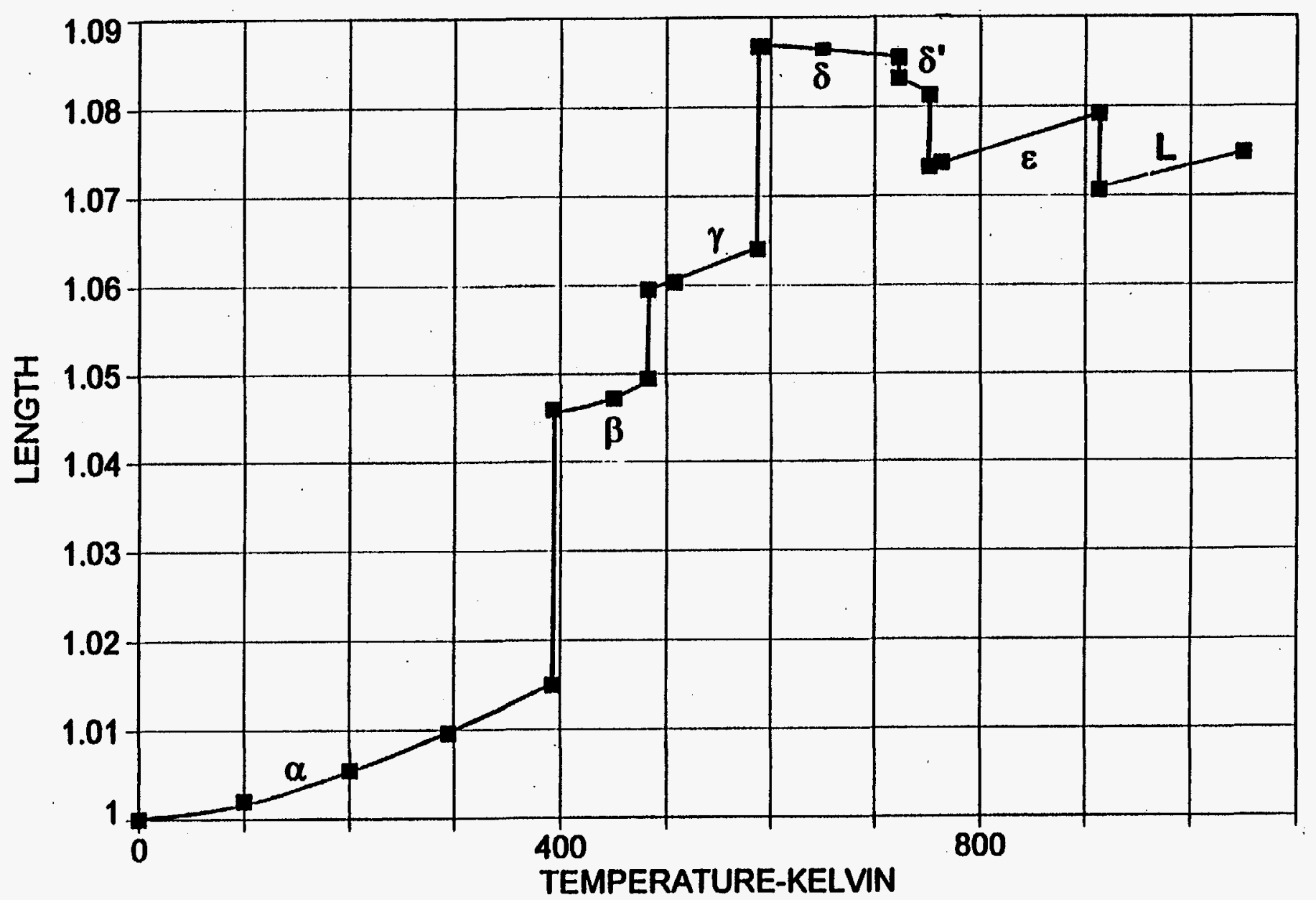

Figure 1 


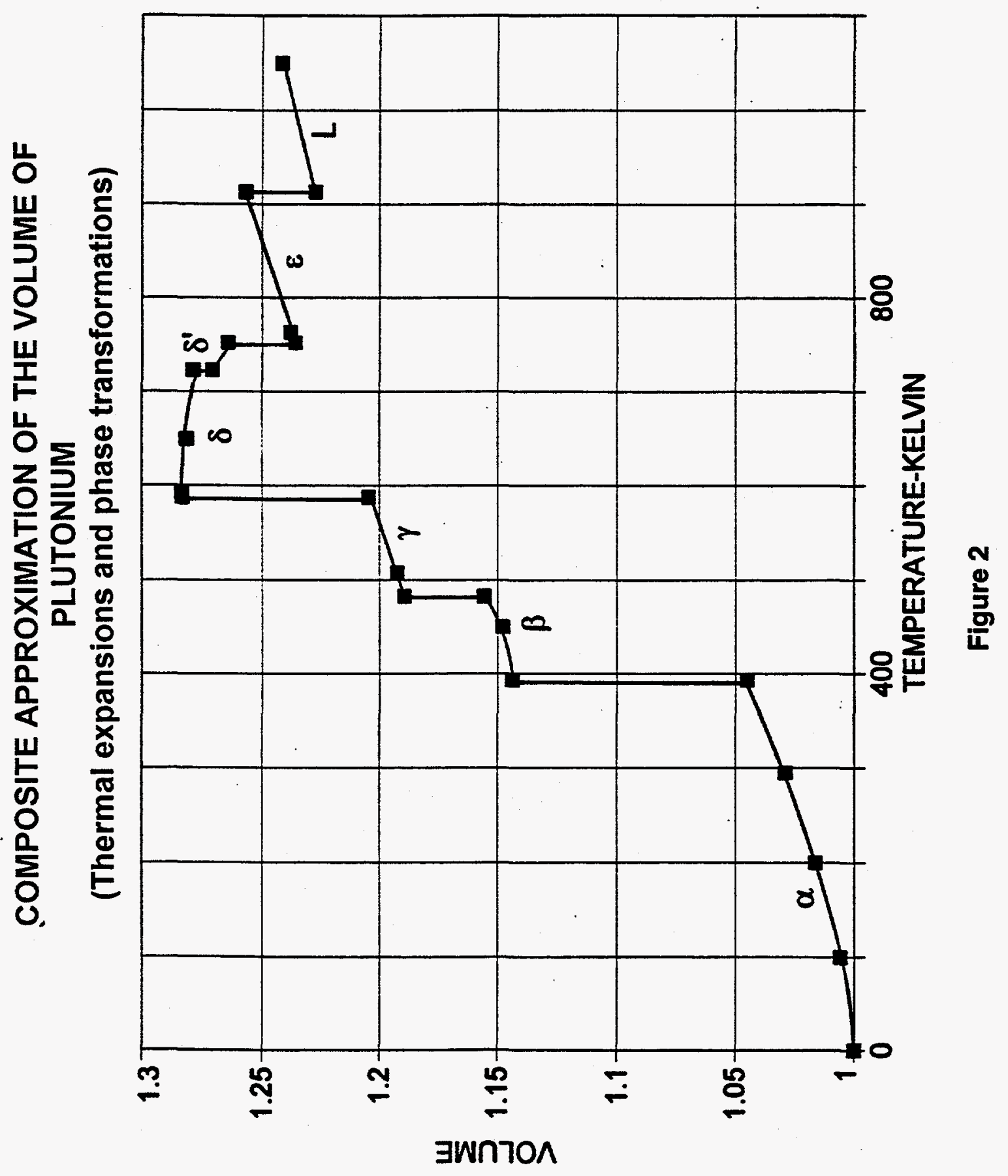




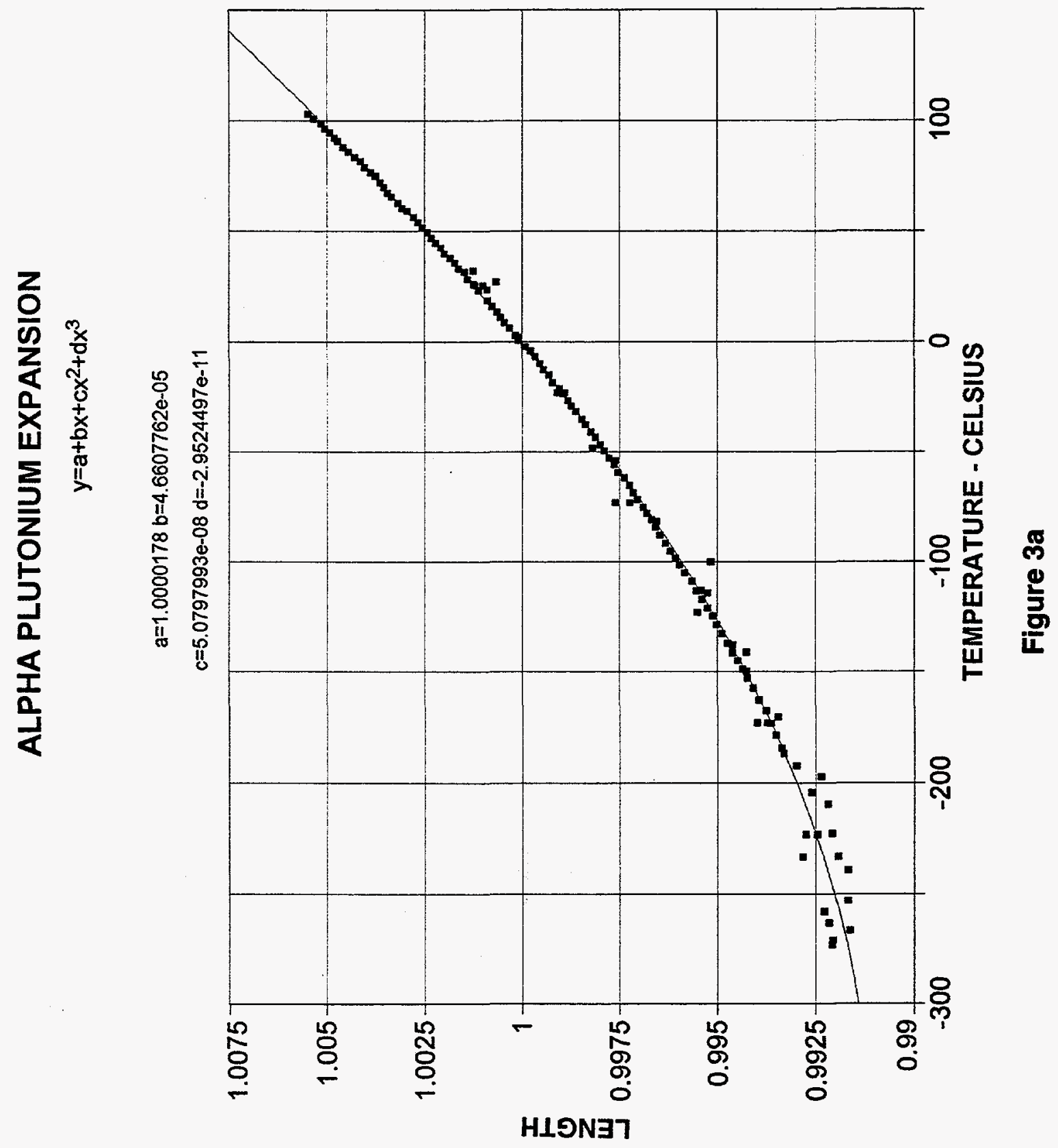




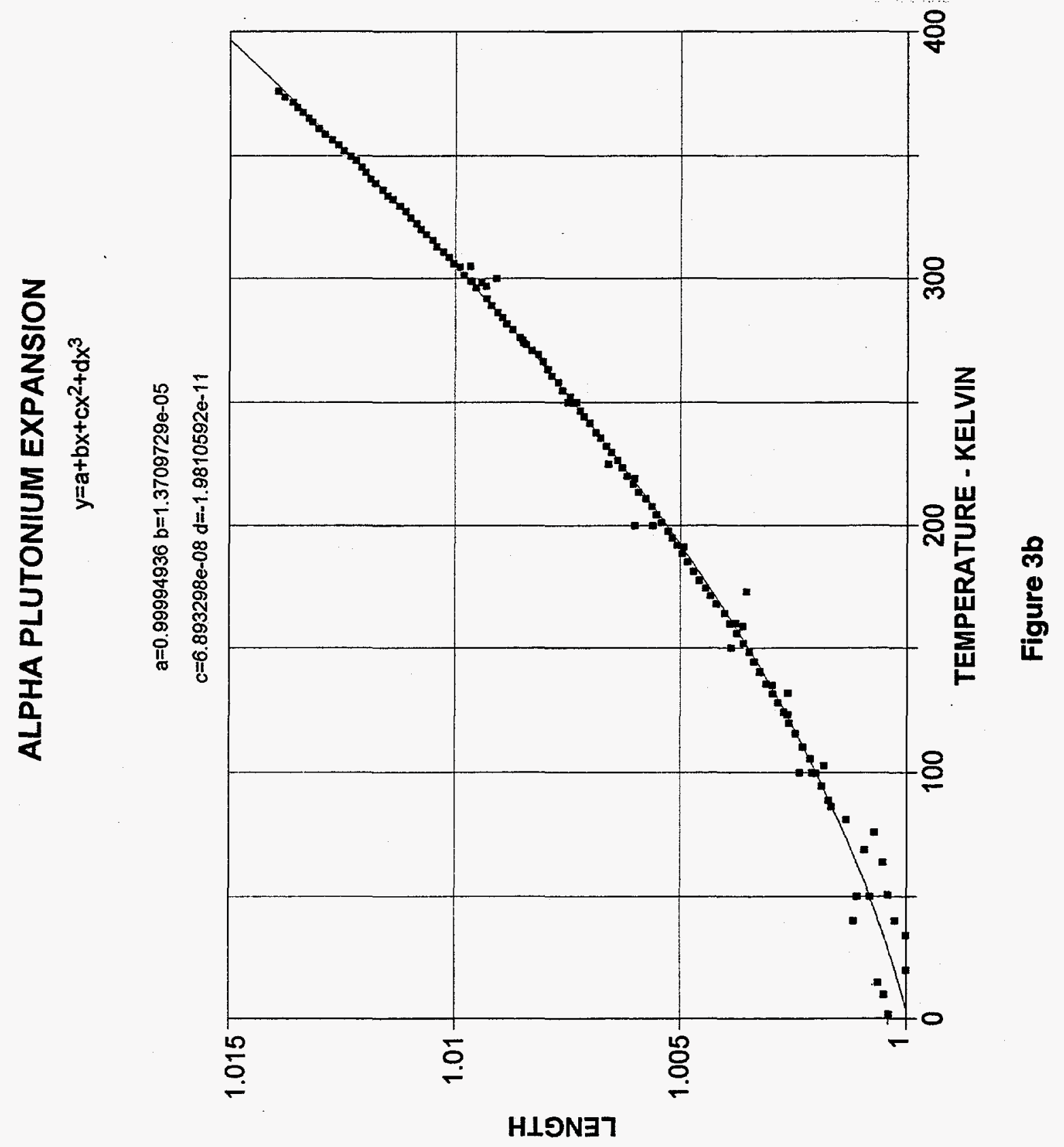




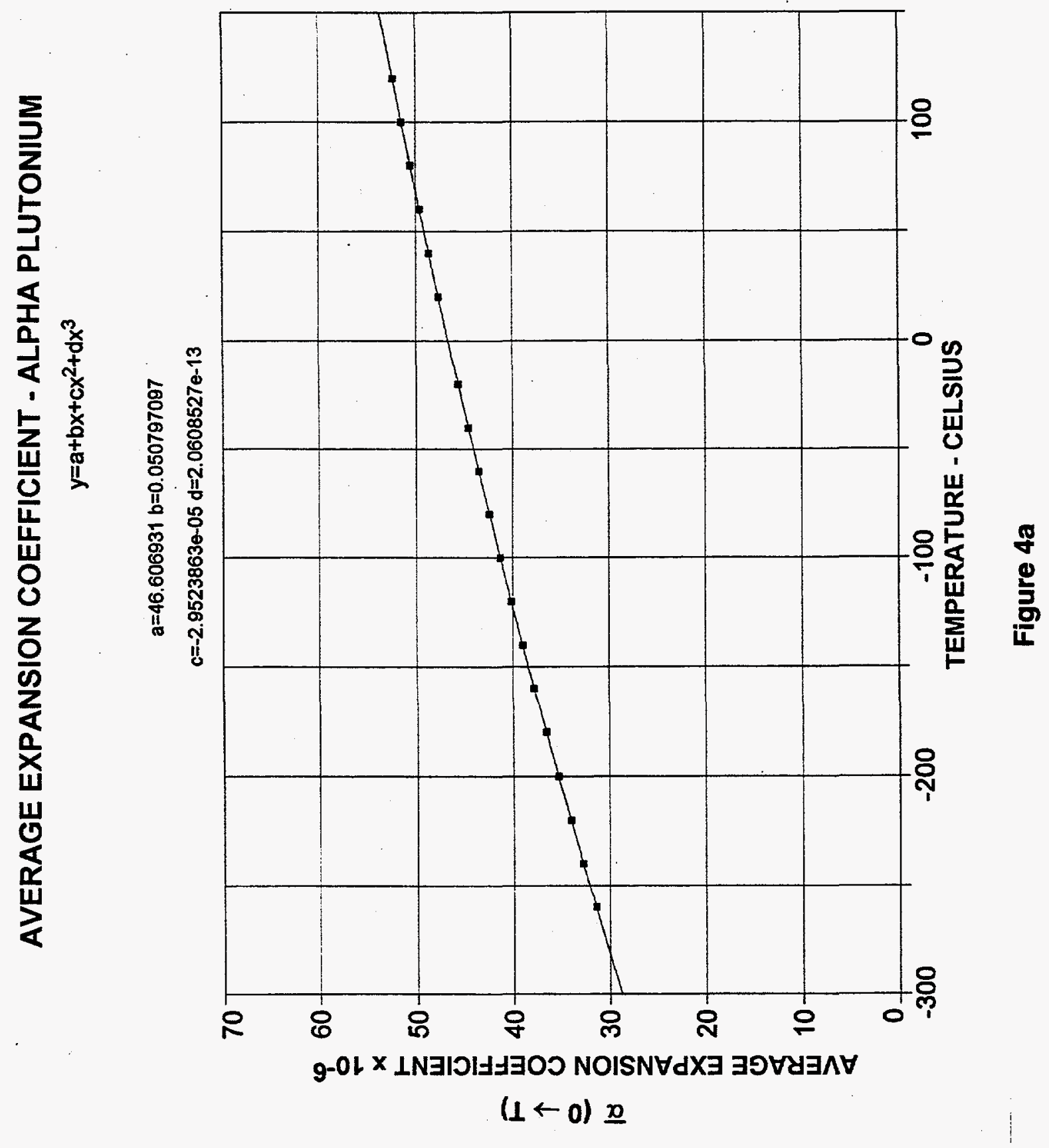




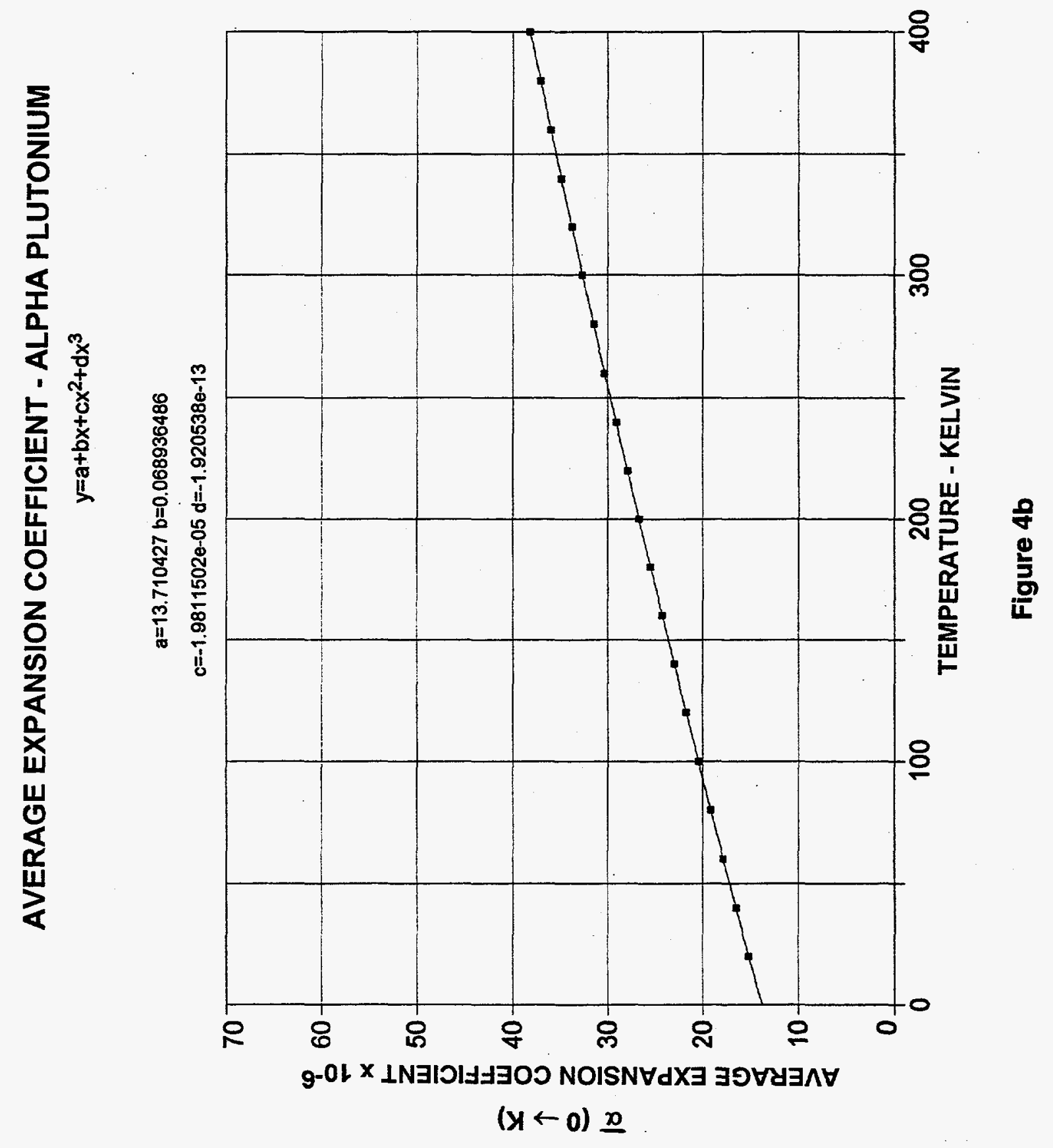




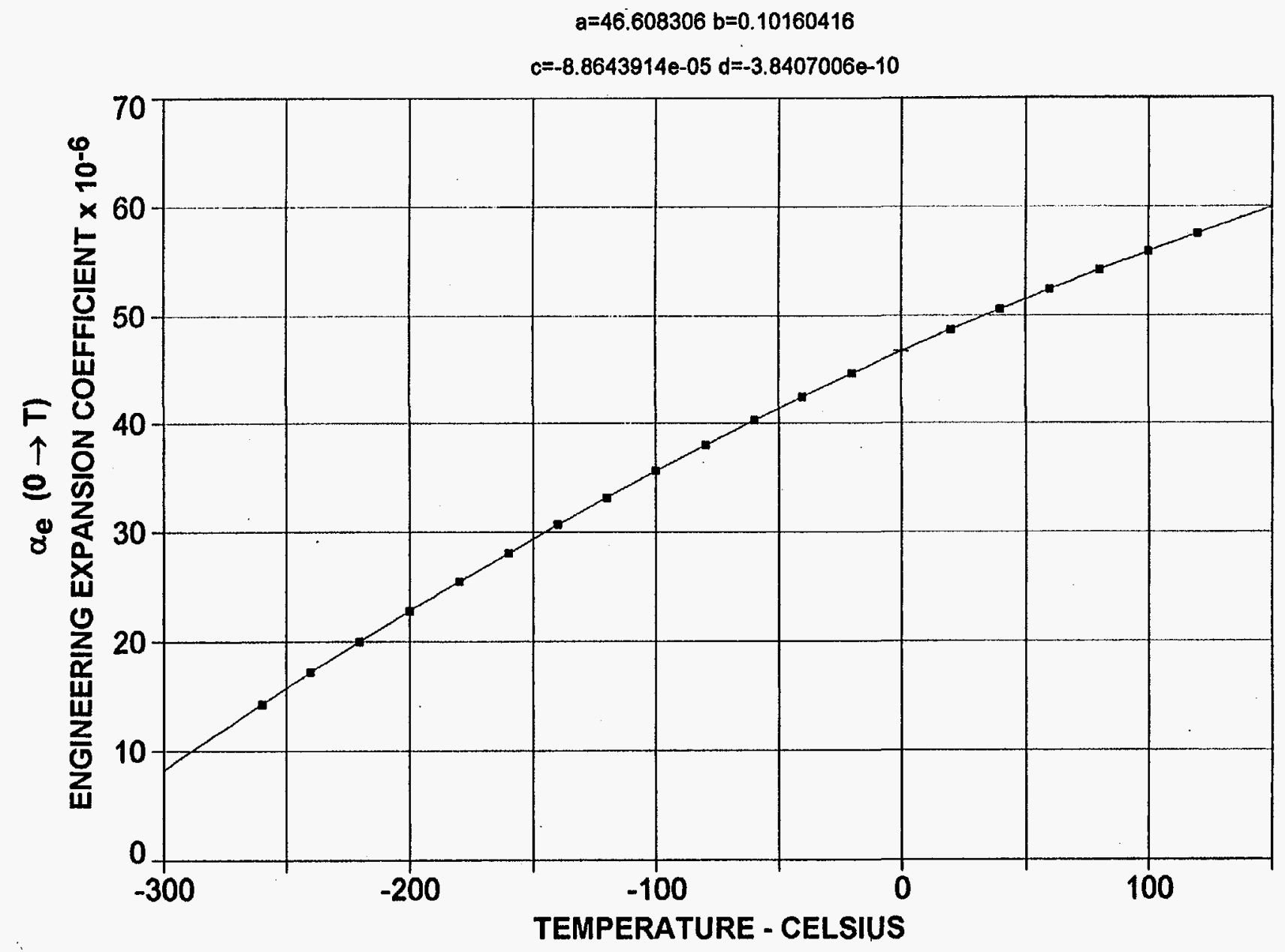

Figure 5a 

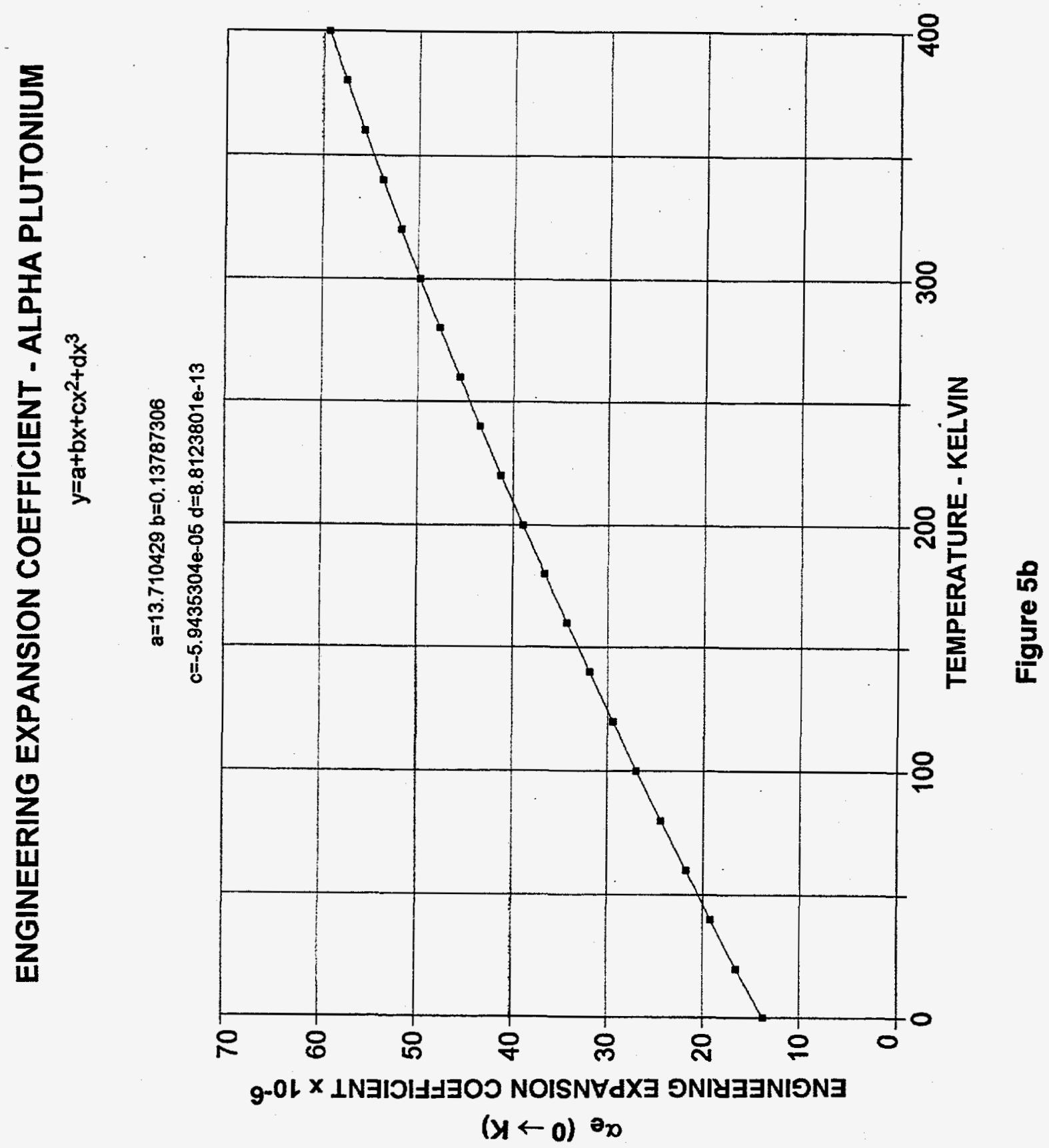


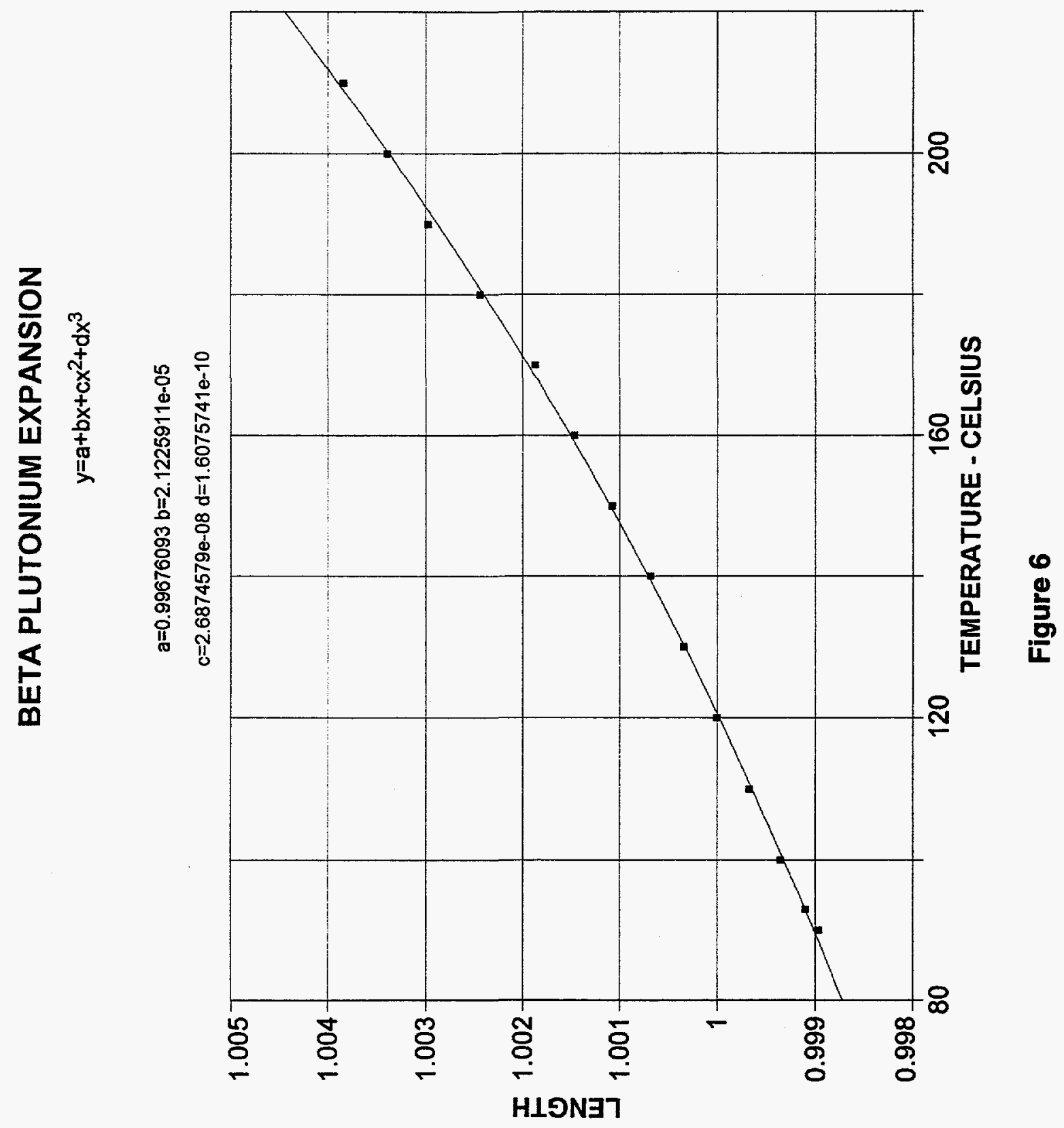




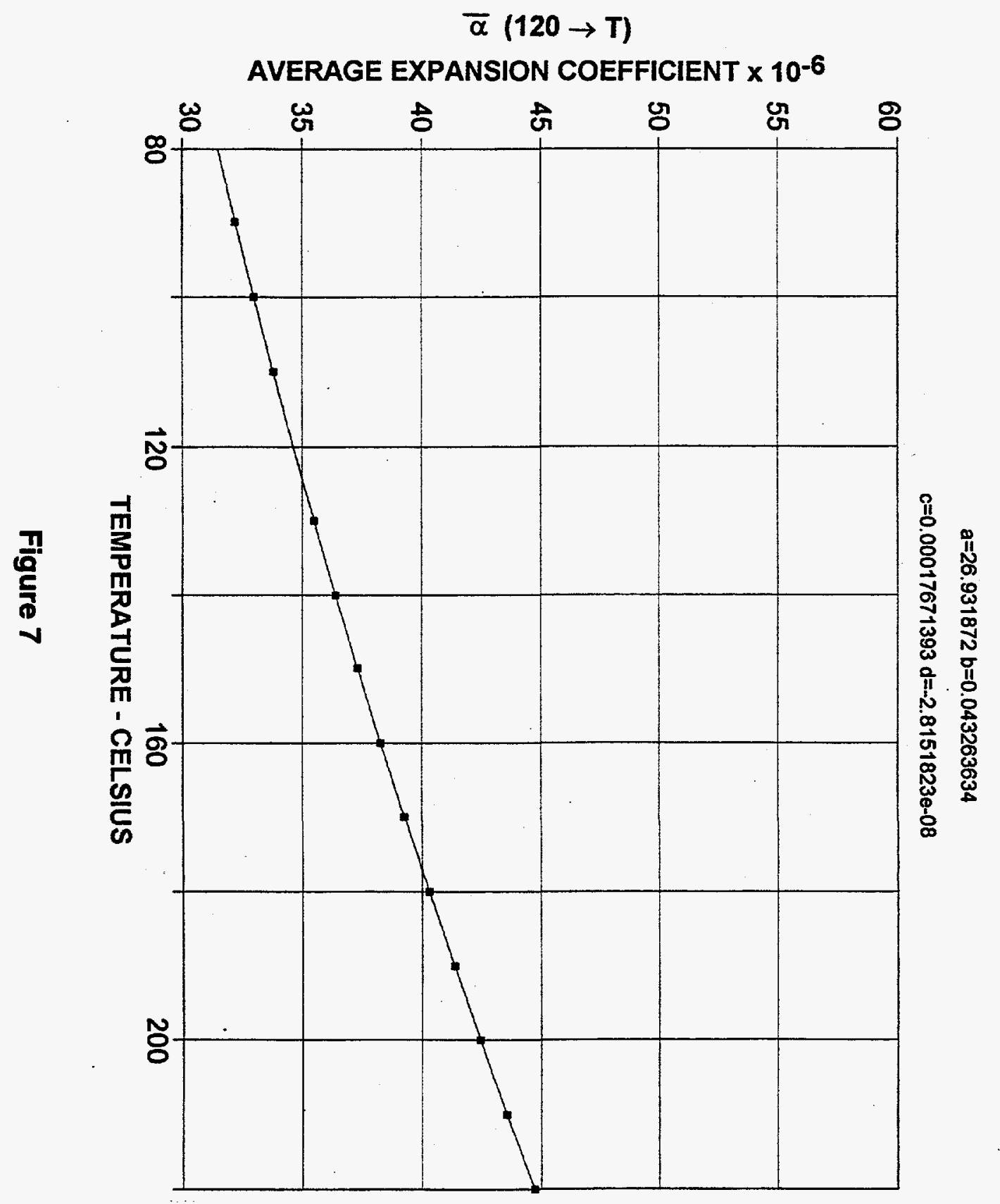


$a=21.226627 b=0.0537476$

$c=0.00048230527 d=-4.2523991 \mathrm{e}-11$

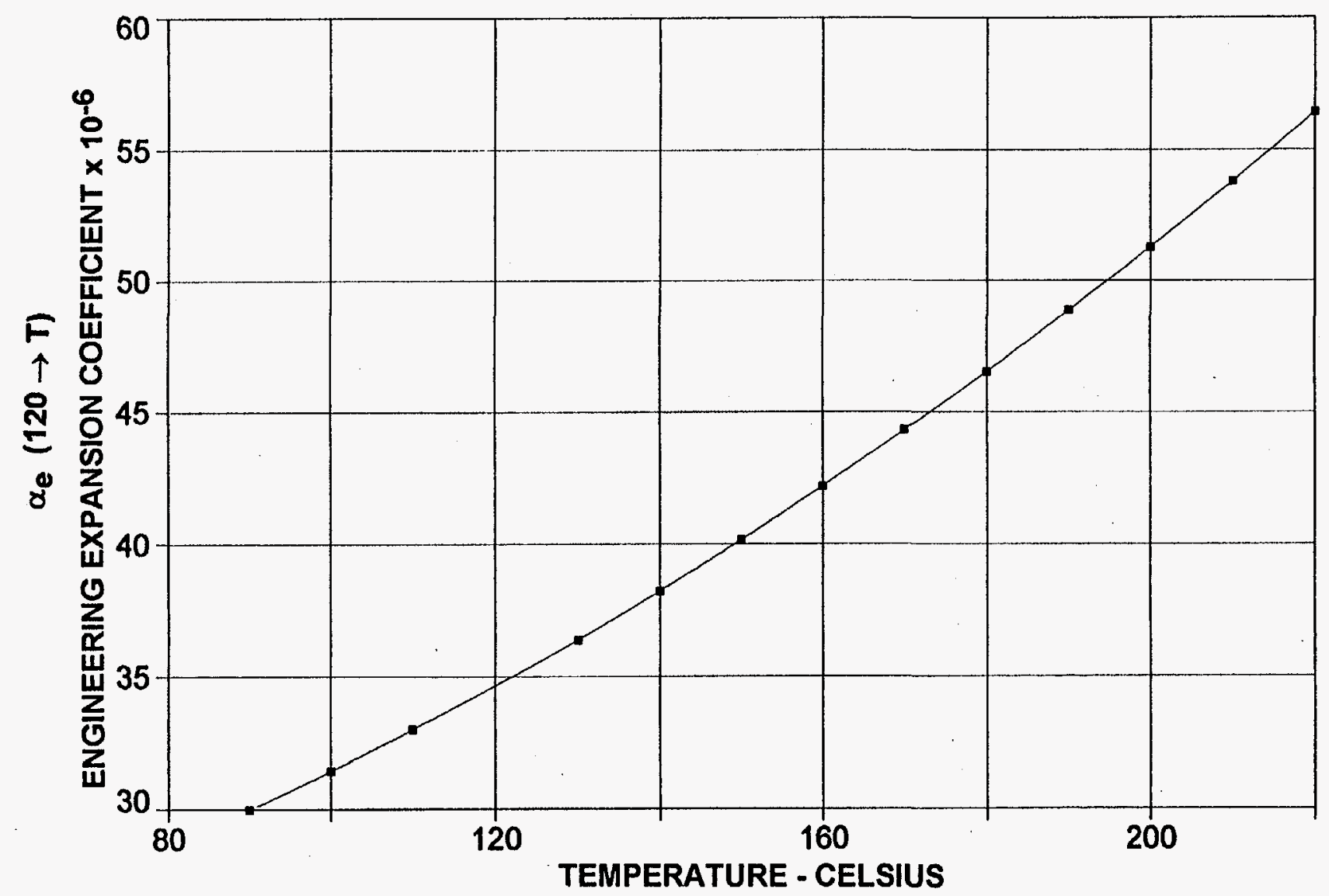

Figure 8 


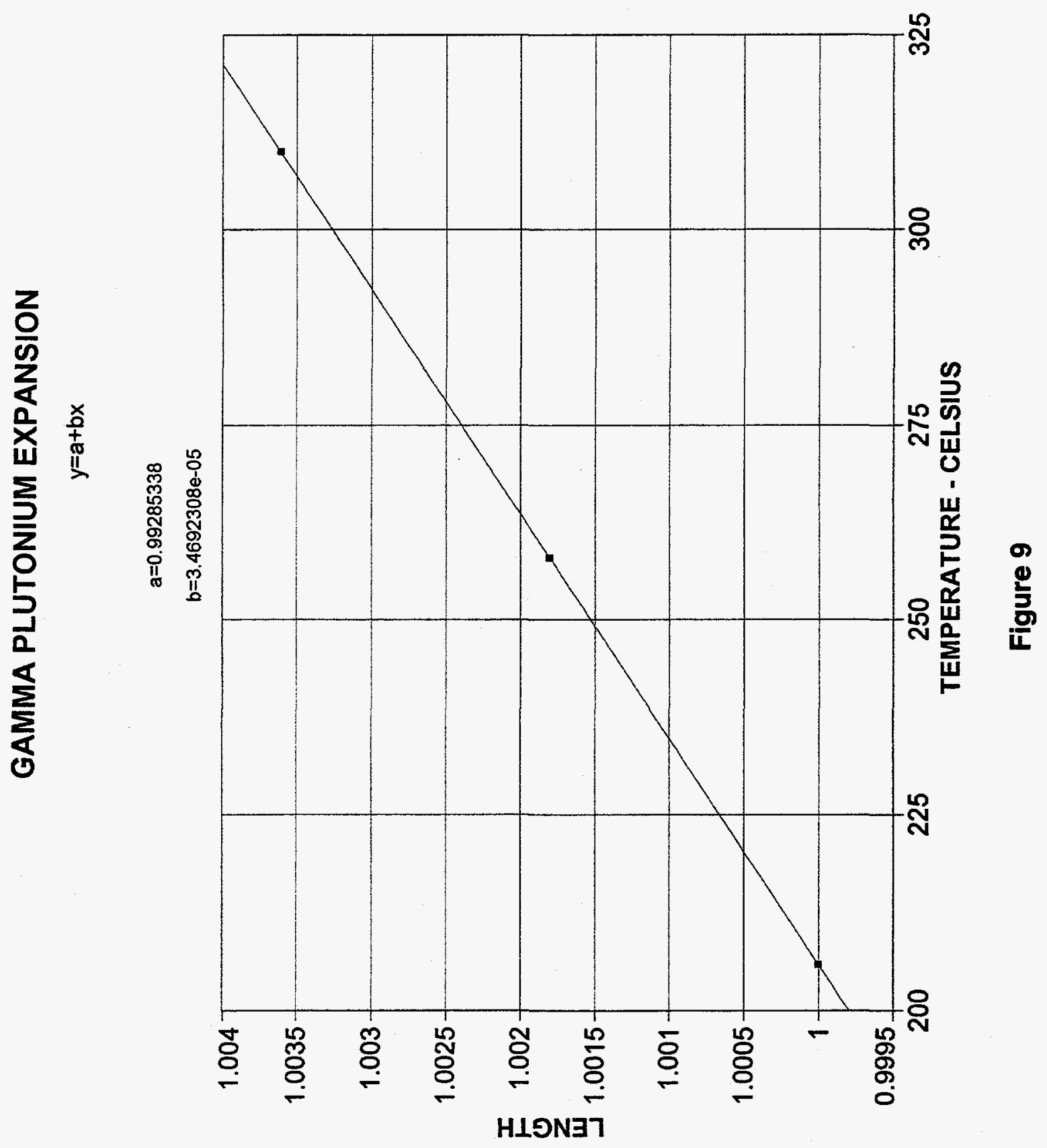




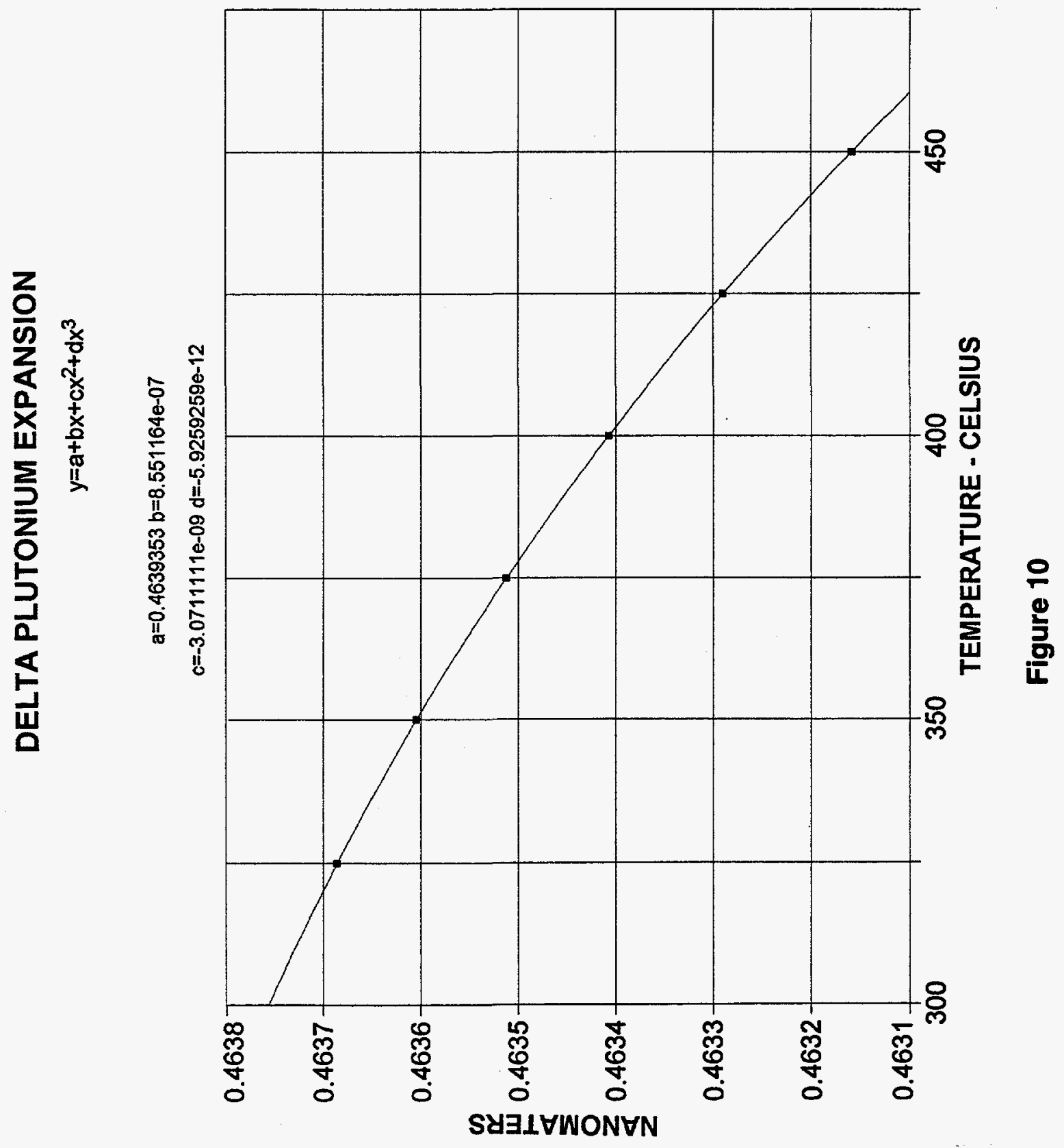




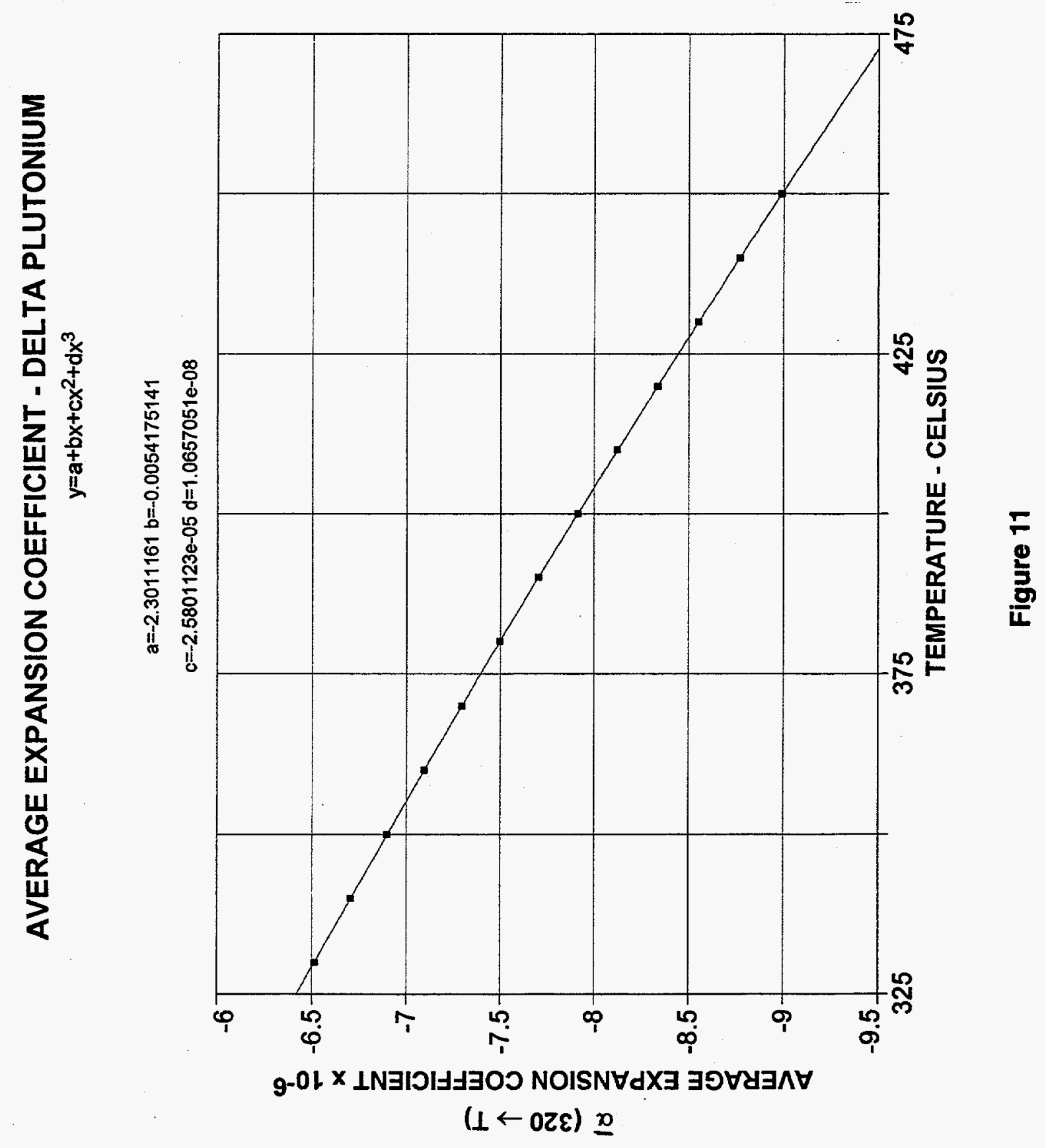


$a=1.8447931 b=-0.013251509$

$c=-3.8324652 \mathrm{e}-05 \mathrm{~d}=-1.2529137 \mathrm{e}-11$

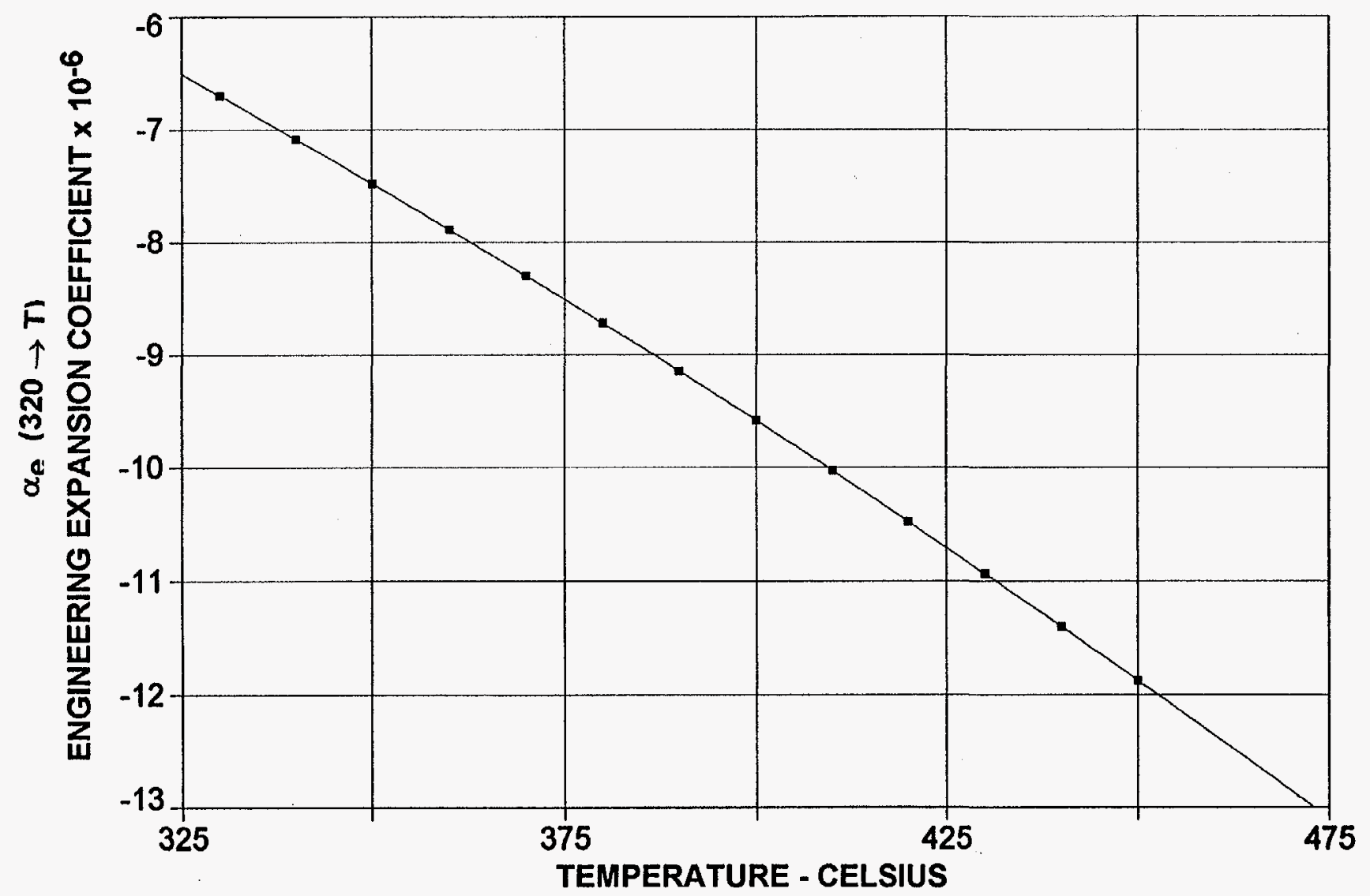

Figure 12 


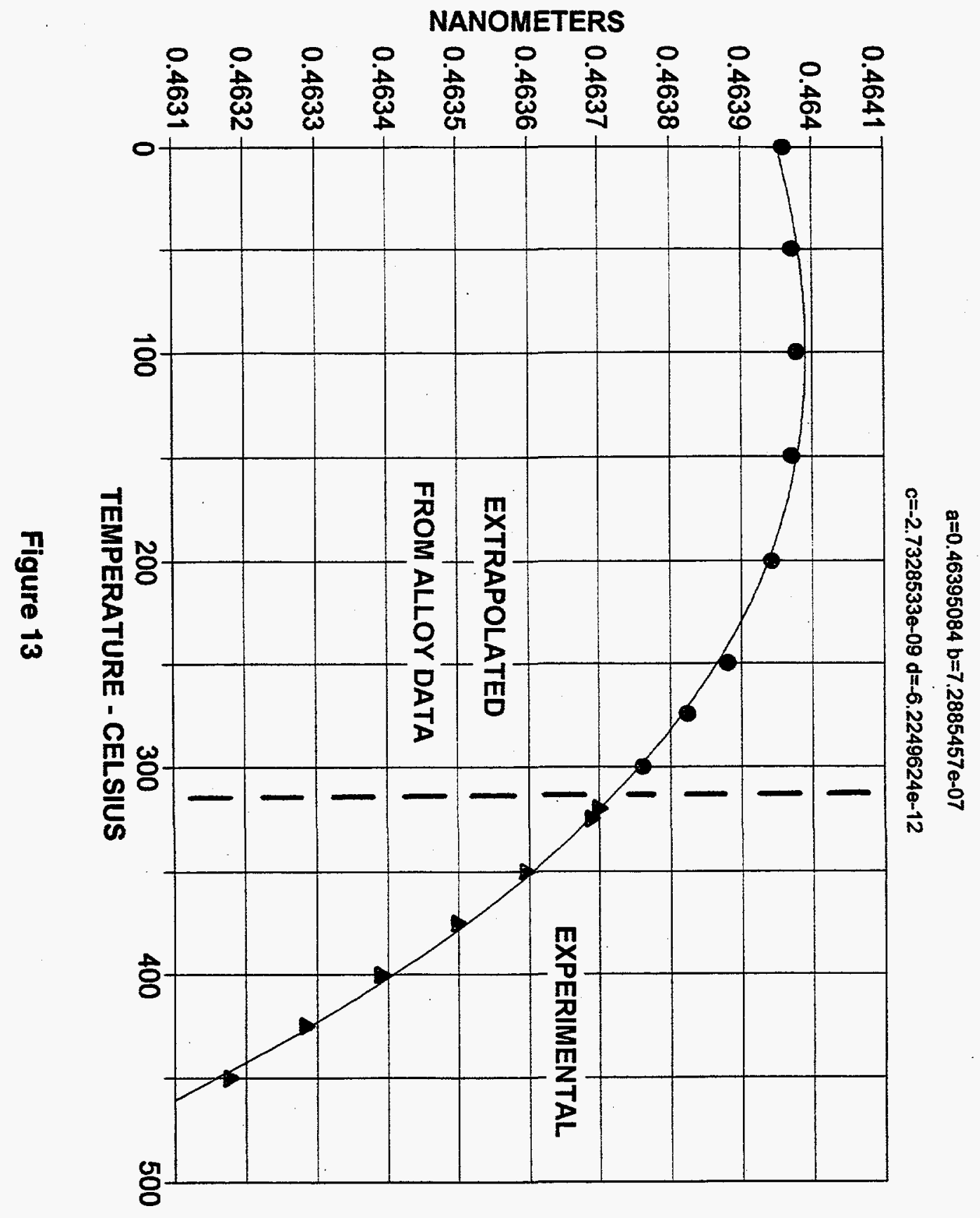

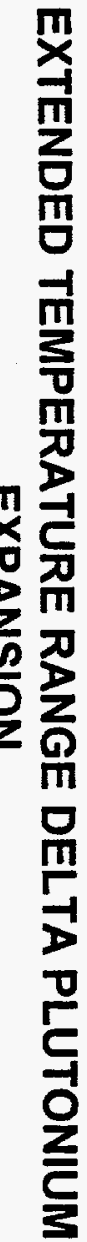



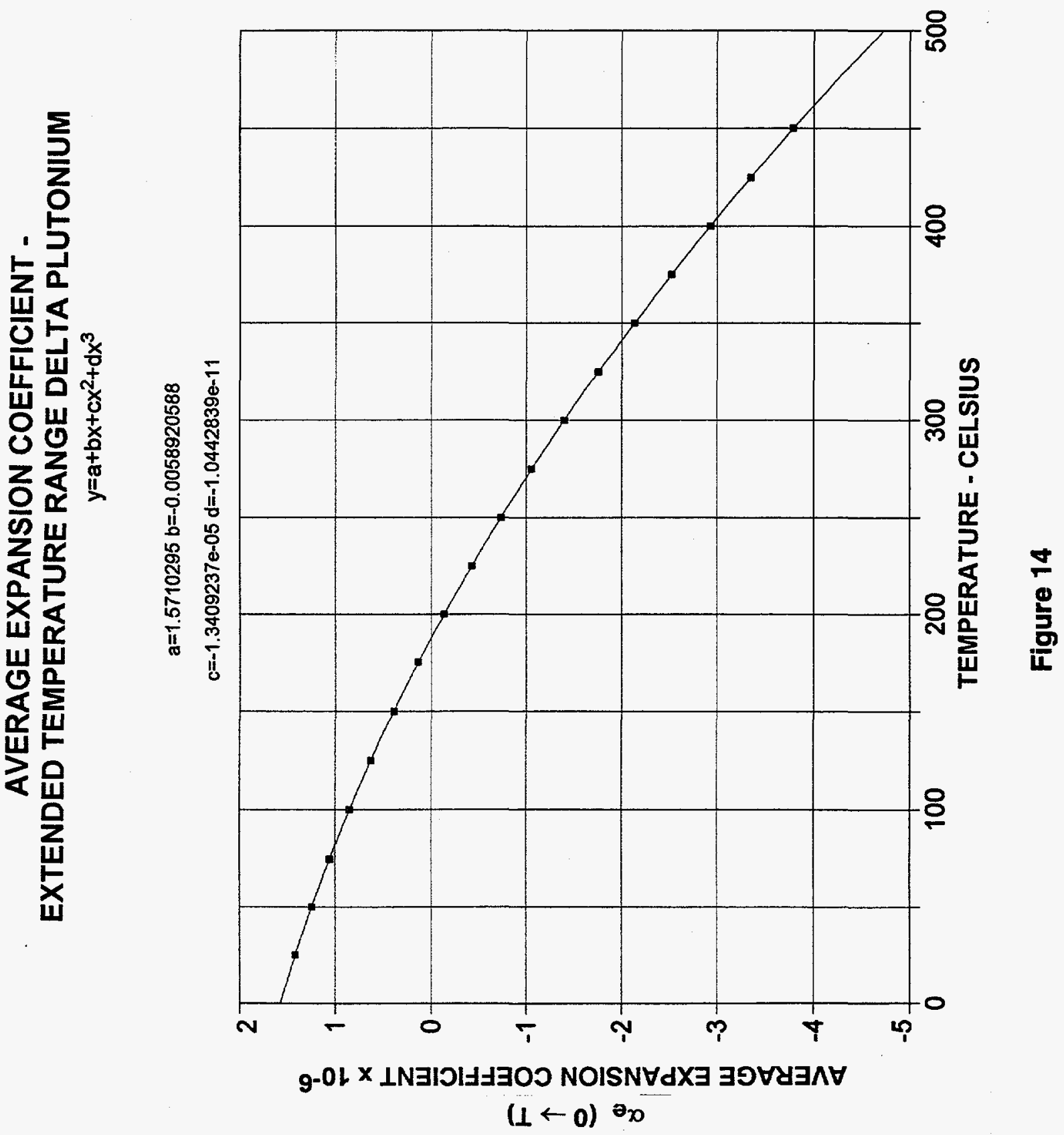

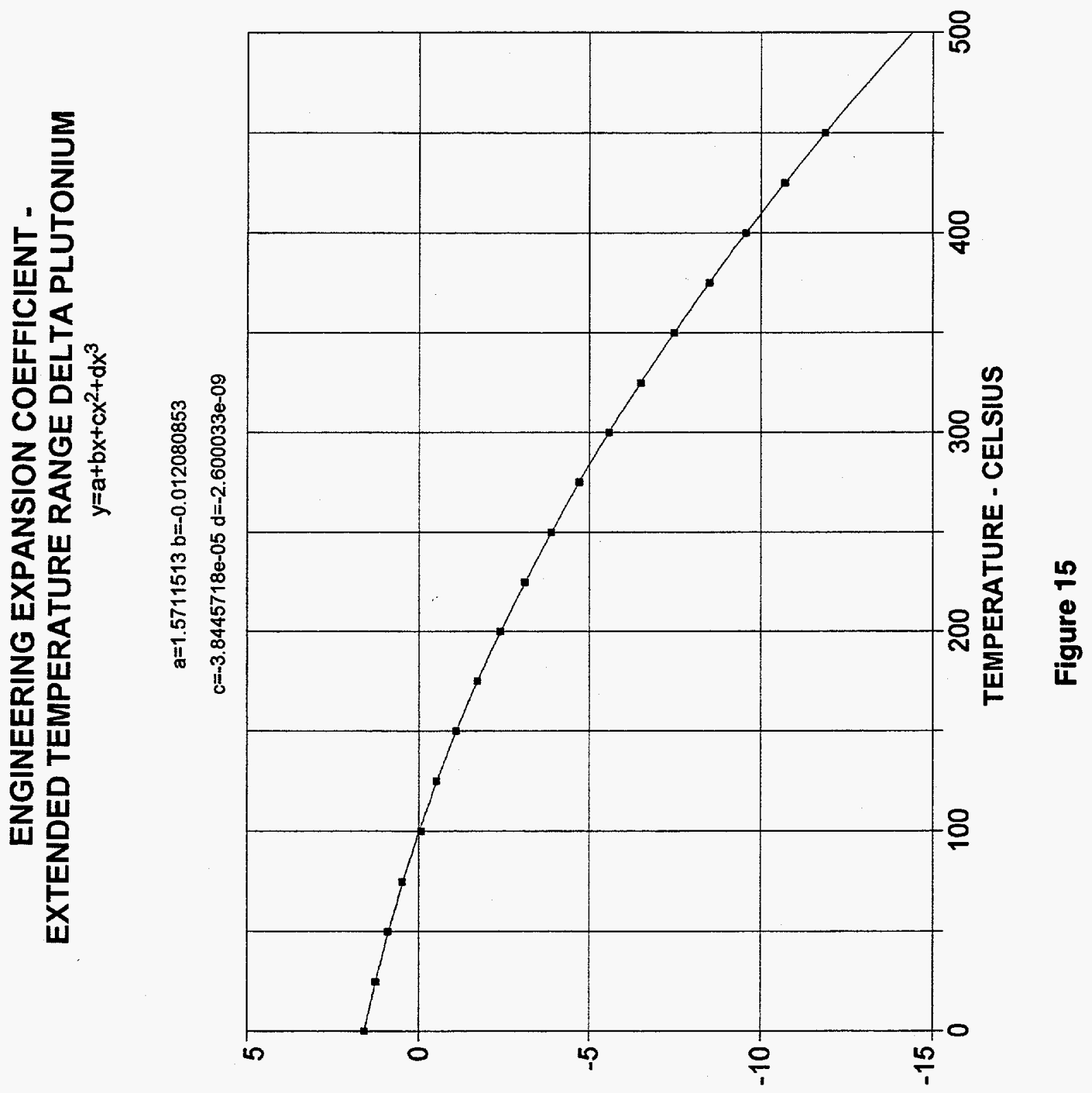

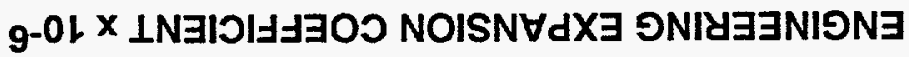

$$
(1 \leftarrow 0) \underline{p}
$$


$y=a+b x+c x^{2}+d x^{3}$

$a=0.98462192 b=0.00010527187$

$c=-1.0980158 \mathrm{e}-07 \mathrm{~d}=-1.058191 \mathrm{e}-10$

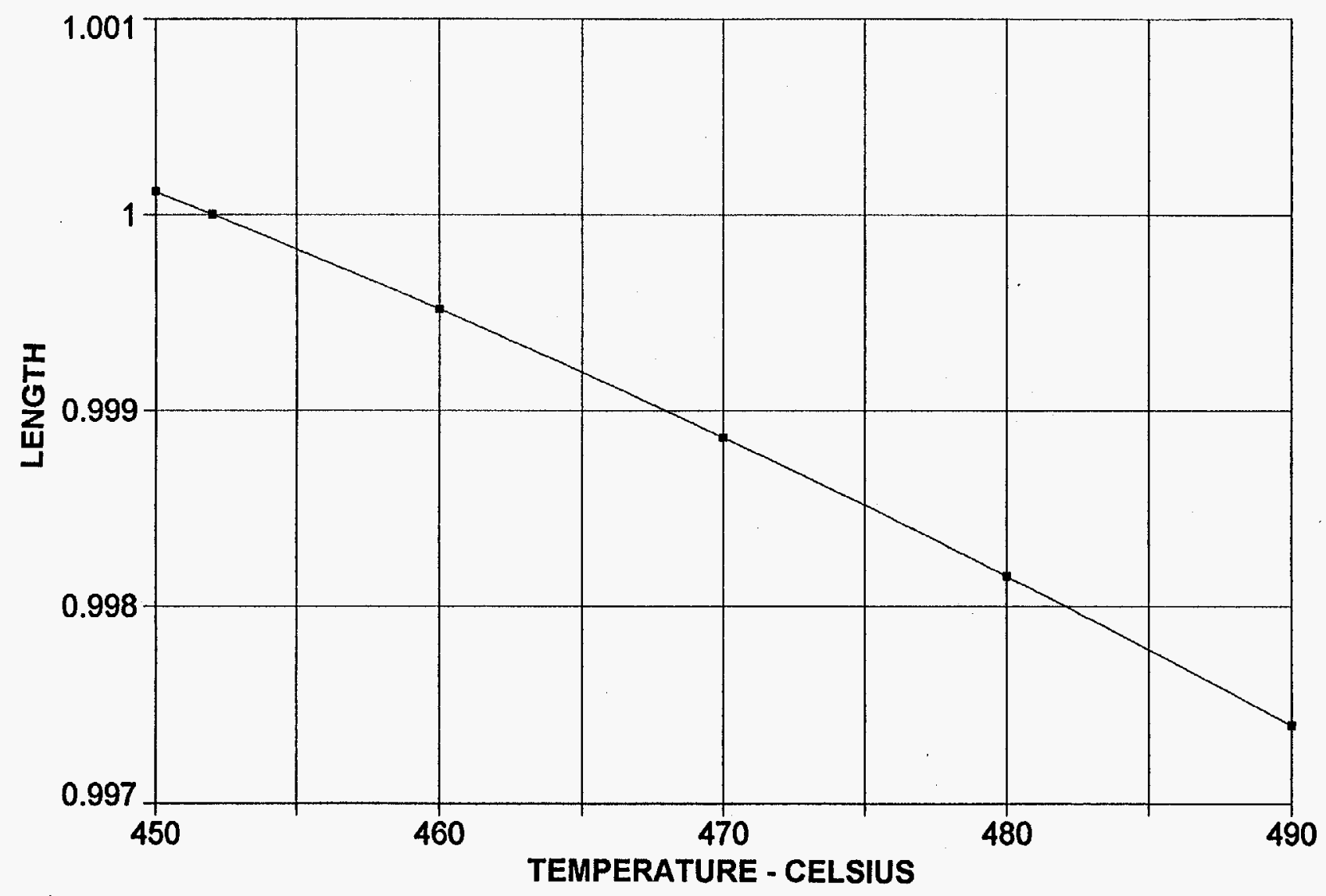

Figure 16 


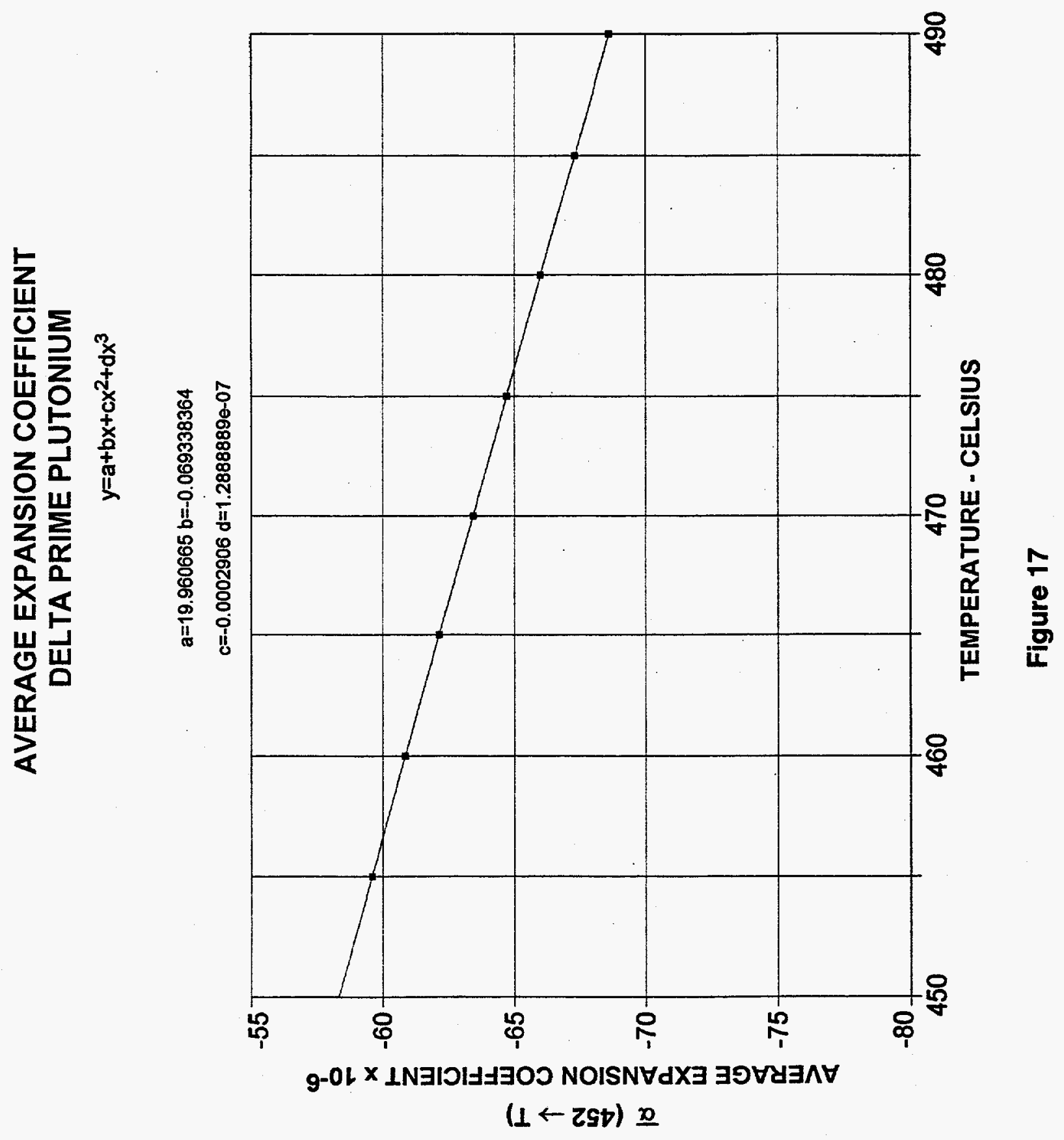




\section{ENGINEERING EXPANSION COEFFICIENT}

- DELTA PRIME PLUTONIUM

$y=a+b x+c x^{2}+d x^{3}$

$a=105.15964 b=-0.21890231$

$c=-0.00031891515 d=1.0101034 \mathrm{e}-09$

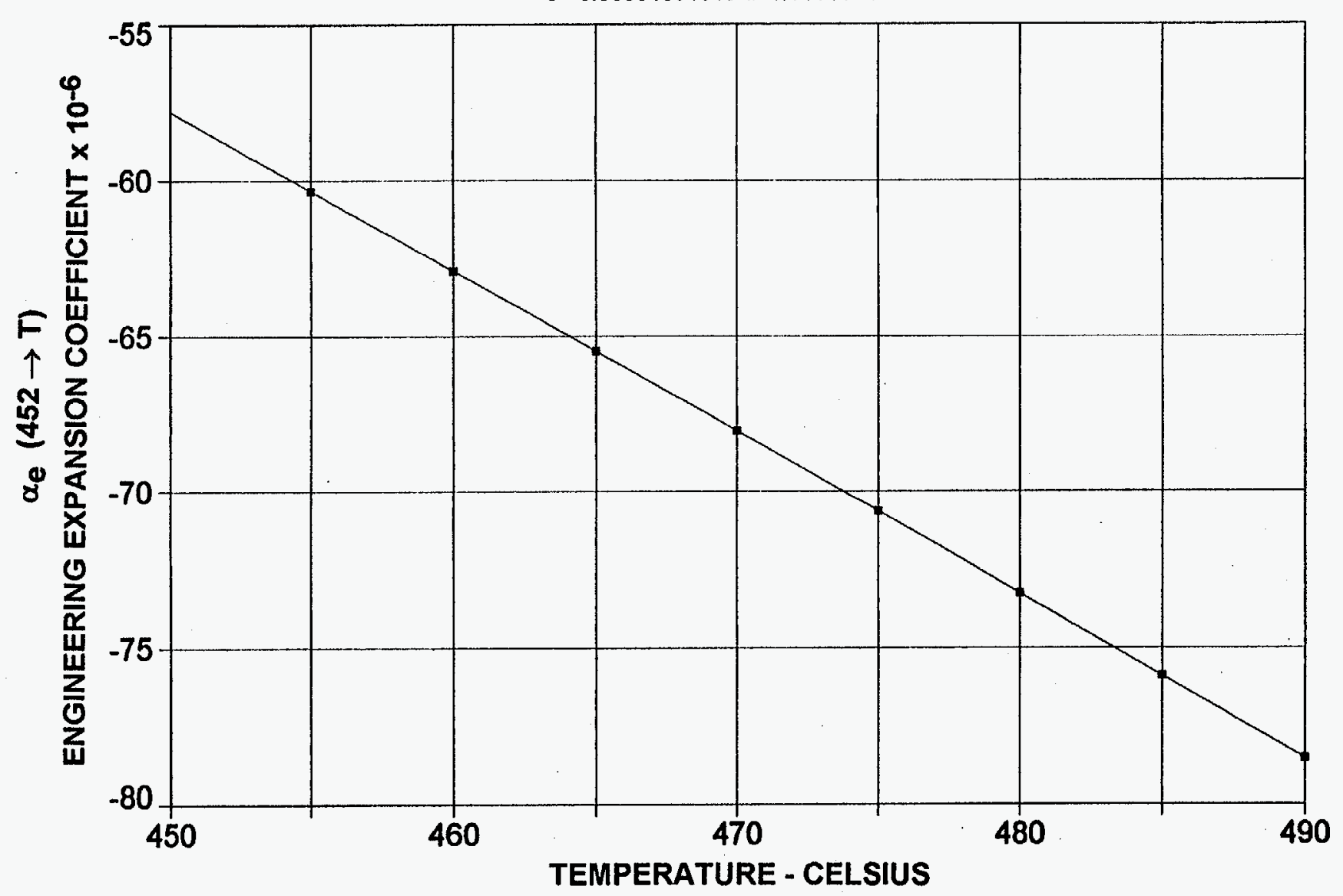

Figure 18 


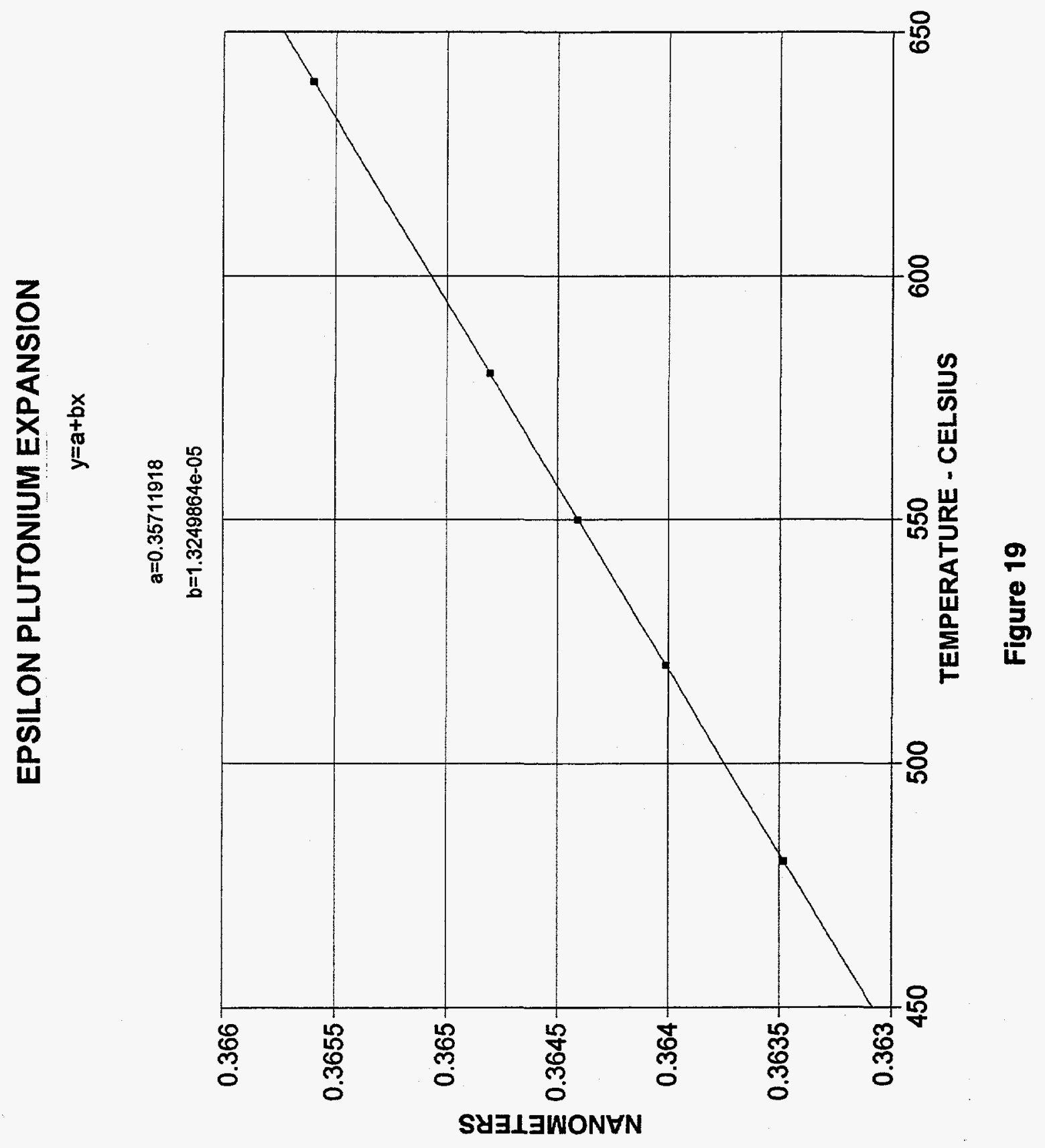




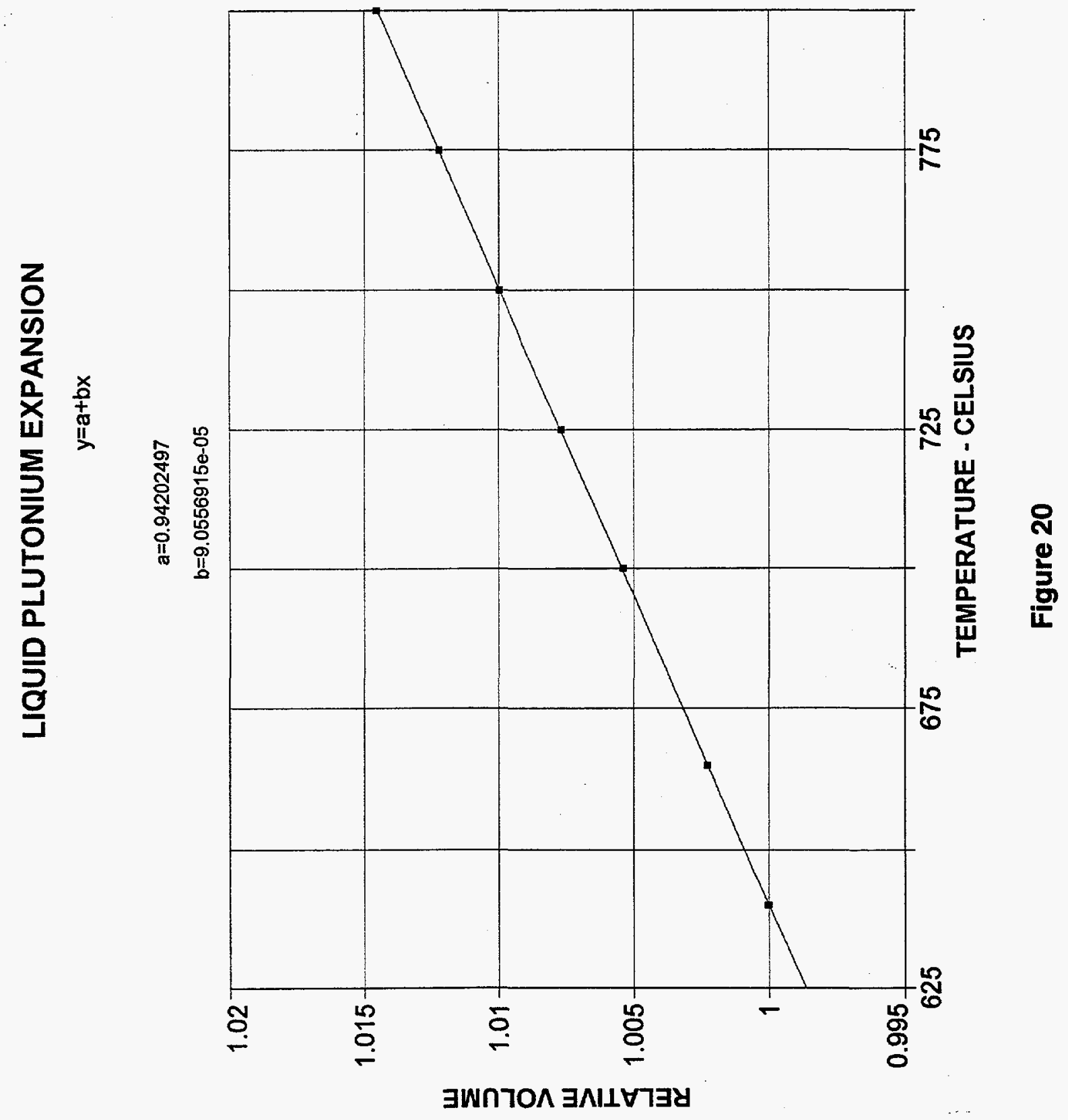




\section{REFERENCES}

Abramson, R., The Metal Plutonium, University of Chicago, Chicago, Illinois, pp. 123-132 (1961).

Cramer, E. M., L. L. Hawes, W. N. Miner, and F. W. Schonfeld, The Metal Plutonium, University of Chicago, Chicago, Illinois, pp. 112-122 (1961).

Ellinger, F. H., Trans AIME, 206, 1256-1259 (1959).

Elliott, R. O., and A. C. Larson, The Metal Plutonium, University of Chicago, Chicago, Illinois, pp. 265-280 (1961).

Hidenert, P., and W. Souder, "Thermal Expansion of Solids," National Bureau of Standards circular 486 (March 1950).

International Union of Crystallography, International Tables for $X$-ray Crystallography, 1, Kynock Press, Birmingham, England (1952).

Jacquemin, J., and R. Lallement, Plutonium 1960, The Metallurgical Society AIME, New York, pp. 616-622 (1970).

Lallement, R., and P. Solente, Plutonium 1965, Chapman and Hall, London, pp. 147-161 (1967).

Lawson, A. C., J. A. Goldstone, B. Cort, R. I. Sheldon, and E. M. Foltyn, J. Alloys \& Compounds, 213/214, 426-428 (1994).

Lee, J. A., and P. G. Marden, The Metal Plutonium, University of Chicago, Chicago, Illinois, pp.133-151 (1961).

Lee, J. A., J. A. C. Marples, K. Mendelssohn, and P. W. Sutcliffe, Plutonium 1965, Chapman and Hall, London, pp.176-188 (1967).

Marples, J. A. C., A. Hough, M. J. Mortimer, A. Smith, and J. A. Lee, Plutonium 1970, The Metallurgical Society AIME, New York, pp. 623-634 (1970).

Nelson, R. D., Plutonium 1965, Chapman and Hall, London, pp. 564-570 (1967).

Olsen, C. E., T. A. Sandenaw, and C. C. Herrick, "The Density of Liquid Plutonium," Los Alamos Scientific Laboratory report LA-2358 (May 1959).

Pascard, R., Plutonium 1960, Cleaver-Hume, London, pp. 16-25 (1961). 
Sandenaw, T. A., Plutonium 1960, Cleaver-Hume, London, pp. 79-90 (1961).

Serpan, C. Z., Jr., and L. J. Wittenberg, Trans AIME 221, 1017-1020 (1961).

Wick, O. J., ed., Plutonium Handbook, Gordon and Breach, New York, p. 36 (1967).

Zachariasen, W. H., and F. H. Ellinger, Acta Cryst. 8, 431-433 (1955).

Zachariasen, W. H., and F H. Ellinger, J. Chem. Phys. 27, 811-812 (1957).

Zachariasen, W. H., and F. H. Ellinger, Acta Cryst. 12, 175-176 (1959).

Zachariasen, W. H., and F H. Ellinger, Acta Cryst. 16, 369-375 (1963).

Zachariasen, W. H., and F H. Ellinger, Acta Cryst. 16, 777-783 (1963). 